\title{
On the power of cross-sectional and multivariate tests of the CAPM
}

\author{
Robert R. Grauer ${ }^{\text {a }}$, Johannus A. Janmaat ${ }^{b}$ \\ ${ }^{a}$ Faculty of Business Administration, Simon Fraser University, Burnaby, British Columbia, \\ Canada V5A 1 S6 \\ ${ }^{b}$ Barber School of Arts and Sciences, University of British Columbia - Okanagan, Kelowna, \\ British Columbia, Canada V1V 1 V7
}

This version: August 15, 2008

\begin{abstract}
This paper examines the power of the cross-sectional and multivariate tests of the CAPM under ideal conditions. When the CAPM is true the positively weighted market portfolio is MVefficient and securities plot on the security market line. When the CAPM is false an alternative asset pricing model determines prices. An examination of the population intercepts, slopes and R-squares from cross-sectional regressions of expected returns on betas indicates that all three are unreliable indicators of whether the CAPM holds. Simulation analysis of the power of the cross-sectional tests expands on and reinforces the analysis based on the population values. The Gibbons, Ross and Shanken (1999) multivariate test fares much better.

JEL classification: G11; G12; C1

Key Words: Portfolio Choice; Asset Pricing; Econometric and Statistical Methods

* Corresponding author. Tel.: +1 778782 3722; fax: +1 7787824920

E-mail addresses: grauer@sfu.ca (R. Grauer), john.janmaat@ubc.ca (J. Janmaat).

Forthcoming in the Journal of Banking and Finance

This version contains an appendix that will not appear in the $J B F$
\end{abstract}




\section{Introduction}

In early tests of the Sharpe (1964) - Lintner (1965) mean-variance capital asset pricing model (MV CAPM), Black, Jensen and Scholes (1972), Blume and Friend (1973) and Fama and MacBeth (1973), among others, find the estimated relationship between average excess return and beta is too flat and the intercept is positive. This led to a consensus that the Sharpe-Lintner riskfree rate version of the CAPM should be rejected and replaced by Black's (1972) zero-beta version. More recently, Fama and French (1992) find that beta alone does not explain the crosssection of expected returns. Rather, size and book-to-market equity combine to capture the crosssectional variation in average stock returns associated with market beta, size, leverage, book-tomarket equity and earnings price ratios. This led to the highly contentious assertion: the CAPM is dead. Subsequently, Fama and French (1993, 1996) develop a three-factor alternative to the CAPM and extensively test both models employing multivariate time-series tests. However, two streams of literature are concerned with the efficacy of the tests. The first stream focuses on econometric issues: developing new testing procedures, extending the tests to conditional models, and examining the power of the tests. The second stream focuses on economic issues and population parameters identifying problems with the tests in a single-period framework.

In the first stream, Jobson and Korkie (1982, 1985), Amsler and Schmidt (1985), MacKinlay (1987, 1995), Gibbons, Ross and Shanken (1989), Affleck-Graves and MacDonald (1990), Campbell, Lo and MacKinlay (1997), among others, examine the power of multivariate tests. Kan and Zhang (1999), Chen and Kan (2006), Lewellen, Nagel and Shanken (2006), Shanken and Zhou (2007), among others, examine the power of cross-sectional tests. Kan and Zhang (1999) highlight a surprising statistical property of the standard two-pass cross-sectional regression methodology: a factor uncorrelated with asset returns will appear to be priced with 
high probability. Lewellen, Nagel and Shanken (2006) contend asset pricing tests are often highly misleading because high cross-sectional R-squares and small pricing errors, when more than one factor is used in explaining average returns on size/book-to-market portfolios, provides quite weak support for a model. Shanken and Zhou (2007) conduct a simulation analysis of the Fama and MacBeth (1973) two-pass procedure, as well as maximum likelihood and generalized method of moments estimators of cross-sectional expected return models. Their simulations show there is little power to reject the hypothesis that the slope of the cross-sectional regression of means on betas is equal to zero. Concurrently, Chen and Kan (2006) provide analytical results on estimation bias as well as simulation evidence. Lo and MacKinlay (1990) and MacKinlay (1995) maintain that the CAPM anomalies may be the result of data snooping. Ferson, Sarkissian and Simin (2008) examine the combined effects of data snooping and spurious regression in conditional asset pricing models. Simin (2008) highlights the poor predictive performance of conditional and unconditional asset pricing models.

In the second stream, Roll (1977) asserts that the CAPM is not testable unless the market portfolio is observable and used in the tests. ${ }^{1}$ Roll and Ross (1994) and Kandel and Stambaugh (1995), reacting to Fama and French's (1992) finding that there is virtually no relationship between expected returns and betas, highlight the danger of focusing exclusively on mean-beta space. Roll and Ross (1994) demonstrate that a market proxy can be almost MV-efficient even though the slope from an ordinary least squares (OLS) regression of population expected returns on population betas is zero. Kandel and Stambaugh (1995) employ a repackaging argument to show that if the index portfolio is inefficient, then the coefficients and R-square from an OLS regression of expected returns on betas can equal essentially any value and bear no relation to

\footnotetext{
${ }^{1}$ Lintner (1965) and Fama (1976), chapters 8 and 9, also discuss this point.
} 
the index portfolio's MV location. Moreover, they show that in a generalized least squares (GLS) regression of mean returns on betas, the slope and R-square are determined uniquely by the MV location of the market index relative to the minimum-variance boundary.

However, neither Roll and Ross nor Kandel and Stambaugh verify whether the minimumvariance frontier contains a positively weighted portfolio. Thus, we cannot be sure whether their results hold if the CAPM is true, i.e., when the positively weighted market portfolio is MVefficient as required by theory. ${ }^{2}$ Grauer (1999) overcomes these shortcomings by examining scenarios where the CAPM is true and where it is false. When the CAPM is true, all the implications of the model are true, i.e., the market portfolio is MV-efficient, securities plot on the security market line (SML), and the positively weighted market portfolio is the tangency portfolio. When the CAPM is true, the findings are not as dramatic as those reported by Roll and Ross or Kandel and Stambaugh. A regression of expected excess returns on betas, calculated against a positively-weighted proxy for the market portfolio, has a flat (but not a zero) slope and a positive intercept. ${ }^{3}$ When the CAPM is false and the market portfolio is almost MV-efficient, the slope of a regression of expected returns on market portfolio betas is zero. When the CAPM is false and the market portfolio is grossly inefficient, regressions employing market portfolio betas may take on exactly the same values as when the model is true.

This paper lies at the confluence of the two streams of the literature. We are the first to examine the power of the cross-sectional and multivariate tests of the CAPM in a setting where all the implications of the CAPM are true. In keeping with simplicity and single-period asset

\footnotetext{
${ }^{2}$ With the exception of one example in Roll and Ross their (inefficient) proxies for the market portfolio do not contain all positive weights either.

3 Grauer and Janmaat (2004) also employ this framework to examine the unexpected consequences of grouping.
} 
pricing models, it is assumed that the sample drawings are taken instantaneously from a fixed joint normal return distribution. Thus, there are no problems with stationarities of any kind, i.e., in returns, betas or weights in the market portfolio. In short, the paper examines the power of the tests with a pure laboratory experiment under ideal conditions that are completely consistent with theory and absent all but the most basic econometric problems. In work that parallels and expands on parts of this paper, Connolly and Rendleman (2007) subsequently and independently report simulations developed from the same set of ideal conditions when the CAPM is true. They quite rightly refer to these ideal conditions as an experiment performed in "the financial economics equivalent of a perfect vacuum" (p. 1). It is disconcerting that both papers find that cross-sectional tests have virtually no power to reject the hypothesis that the slope of a regression of average excess returns on betas is equal to zero when the CAPM is true.

We are also the first to examine the power of the tests where an alternative asset pricing model determines prices when the CAPM is false. We formulate the CAPM and Fama-French (FF, hereafter) three-factor model as MV problems whose first-order conditions are the pricing equations. More importantly, we show how to reverse engineer the pricing equations to ensure that the market portfolio is either MV- or multifactor-efficient. Serendipitously (and perhaps surprisingly), the CAPM may be viewed as a special case of the FF three-factor model. This allows us to construct a large number of economies consisting of 25 book-to-market/size portfolios, where the three-factor model—and in a special case the CAPM—hold exactly. In these single-period economies, the weights in the "market" portfolio and in the small minus big $(S M B)$ and high minus low ( $H M L)$ portfolios are clearly identified. By varying the expected returns of the $S M B$ and $H M L$ portfolios in the three-factor model pricing equation we create a 
rich environment where the CAPM may be absolutely correct, almost correct, or patently false. ${ }^{4}$ An examination of the population intercepts, slopes and R-squares from cross-sectional regressions of expected returns on betas indicates that all three are unreliable indicators of whether the CAPM holds. Simulation analysis of the power of the cross-sectional tests expands on and reinforces the analysis based on population values. The Gibbons, Ross and Shanken (1999) multivariate test fares much better.

The paper proceeds as follows. In Section 2 we formulate the CAPM and FF three-factor model as MV problems whose first-order conditions are the pricing equations and show how to construct means that ensure the market portfolio is either MV- or multifactor-efficient. We then describe the data used to set the population parameters in the economies, and present the population parameters in two cases-when the CAPM is true and when the FF three-factor model is true with the FF pricing equation parameters set equal to their historic values. Finally we show by example that setting population means from the SML with betas estimated from time-series regressions, as is often done in simulation experiments, does not guarantee that the market portfolio is MV-efficient as required by theory. Section 3 reviews cross-sectional and multivariate tests of the CAPM and explains how the simulations are conducted. Section 4 presents the results for univariate cross-sectional and multivariate tests of the CAPM. Section 5 contains the results for tests of whether beta alone explains the cross-section of expected returns in two cases: when the CAPM is true and the FF three-factor model is true with the FF pricing equation parameters set equal to their historic values. Section 6 summarizes the paper and offers concluding comments.

4 Some of the examples in Roll and Ross (1994), Kandel and Stambaugh (1995) and Grauer (1999) may appear to be extreme or in some sense pathological. However, our results indicate that they may arise when the alternative to the CAPM is another asset pricing model. 


\section{Configuring the CAPM and FF three-factor model economies}

In this section we state the CAPM and FF three-factor pricing equations and show how to reverse engineer them to construct the economies. The CAPM pricing equation (the SML) is

$$
\boldsymbol{\mu}_{C A P M}=r \mathbf{l}+\left(\mu_{m}-r\right) \boldsymbol{\beta}_{m},
$$

where $\boldsymbol{\mu}, \mathbf{\imath}$ and $\boldsymbol{\beta}_{m}$ are $n$-vectors containing expected rates of return, ones and betas, $r$ is the riskfree rate of interest and $\mu_{m}$ is the expected rate of return on the market portfolio. Let $\boldsymbol{\Sigma}$ be an $n \times n$ positive-definite covariance matrix of asset returns. Then, $\Sigma \mathbf{x}_{m}$ is an $n$-vector whose $j$ th element $\operatorname{cov}\left(r_{j}, r_{m}\right)$ is the covariance of the return on security $j$ with the return on the market portfolio and $\boldsymbol{\beta}_{m}=\boldsymbol{\Sigma} \mathbf{x}_{m} / \sigma_{m}^{2}$, whose $j$ th element is $\beta_{j}=\operatorname{cov}\left(r_{j}, r_{m}\right) / \sigma_{m}^{2}$. The SML is closely associated with the $N$ time-series regressions

$$
r_{j t}-r_{t}=\alpha_{j}+\left(r_{m t}-r_{t}\right) \beta_{j}+e_{j t}
$$

where $r_{j t}$ and $r_{m t}$ are the return on asset $j$ and the market portfolio at time $t$. The FF three-factor model pricing equation is

$$
\boldsymbol{\mu}_{F F}=r \mathbf{\imath}+\left(\mu_{m}-r\right) \mathbf{b}_{m}+\mu_{S M B} \mathbf{b}_{S M B}+\mu_{H M L} \mathbf{b}_{H M L},
$$

where $\mathbf{b}_{m}, \mathbf{b}_{S M B}$ and $\mathbf{b}_{\text {HмL }}$ are $n$-vectors containing the factor sensitivities of the securities to the market, $S M B$ and $H M L$ portfolios, and $\mu_{S M B}$ and $\mu_{H M L}$ are the expected returns of the $S M B$ and $H M L$ portfolios. The FF pricing equation is closely associated with the $N$ time-series regressions

$$
r_{j t}-r_{t}=\alpha_{j}+\left(r_{m t}-r_{t}\right) b_{m j}+r_{S M B t} b_{S M B j}+r_{H M L t} b_{H M L j}+e_{j t},
$$

where $r_{S M B t}$ and $r_{H M L t}$ are the returns on $S M B$ and $H M L$ at time $t$.

We configure the economies by reverse engineering the first-order conditions to MV problems. The CAPM holds when the market portfolio is a representative investor's solution to 


$$
\max L=T \boldsymbol{\mu}^{\prime} \mathbf{x}+\operatorname{Tr} x_{r}-1 / 2 \mathbf{x}^{\prime} \mathbf{\Sigma} \mathbf{x}+\lambda\left(1-\mathbf{\imath}^{\prime} \mathbf{x}-x_{r}\right),
$$

where $\mathbf{x}$ is an $n$-vector of portfolio weights, $\lambda$ is the Lagrange multiplier associated with the budget constraint $\mathbf{\imath} \mathbf{x}+x_{r}=1, x_{r}$ is the fraction of wealth either lent or borrowed, and $T$ is a scalar risk tolerance parameter. Best and Grauer (1985) showed: if the covariance matrix and vector of weights in the market portfolio are given and we choose the intercept and slope in equation (1), then the resulting means, when substituted into equation (5) together with the covariance matrix, guarantee that the market portfolio is MV-efficient.

Fama (1996) shows that Merton's (1973) intertemporal capital asset pricing model, like the CAPM, holds when the market portfolio is the optimal solution to a constrained MV problem. The FF three-factor model holds as a special case when the market portfolio is a representative investor's solution to

$$
\max L=T \boldsymbol{\mu}^{\prime} \mathbf{x}+t r x_{r}-(1 / 2) \mathbf{x}^{\prime} \mathbf{\Sigma} \mathbf{x}+\lambda\left(1-\mathbf{l}^{\prime} \mathbf{x}-x_{r}\right)+\lambda_{\text {SMB }}\left(\sigma_{m S M B}-\mathbf{x}^{\prime} \mathbf{\Sigma} \mathbf{x}_{S M B}\right)+\lambda_{H M L}\left(\sigma_{m H M L}-\mathbf{x}^{\prime} \mathbf{\Sigma} \mathbf{x}_{H M L}\right),
$$

where the $j$ th elements of $\mathbf{\Sigma} \mathbf{x}_{S M B}$ and $\mathbf{\Sigma} \mathbf{x}_{H M L}$ are $\operatorname{cov}\left(r_{j}, r_{S M B}\right)$ and $\operatorname{cov}\left(r_{j}, r_{H M L}\right)$, $\sigma_{m S M B}=\mathbf{x}_{m}{ }^{\prime} \boldsymbol{\Sigma} \mathbf{x}_{S M B}=\operatorname{cov}\left(r_{m}, r_{S M B}\right), \sigma_{m H M L}=\mathbf{x}_{m}{ }^{\prime} \mathbf{\Sigma}_{\mathbf{x}_{H M L}}=\operatorname{cov}\left(r_{m}, r_{H M L}\right)$ and $\lambda, \lambda_{S M B}$ and $\lambda_{H M L}$ are Lagrange multipliers. In an appendix available from the authors, we showed: if the covariance matrix and vectors of weights in the market, $S M B$ and $H M L$ portfolios are given and we choose the intercept and slopes from equation (3), then the resulting means, when substituted into equation (6) together with the covariance matrix, guarantee that the market portfolio is multifactor efficient.

We configure the economies using data from the 25 book-to-market/size portfolios in Kenneth French's data library to construct population parameters. The first step is to specify the weights in the market, $S M B$ and $H M L$ portfolios. We calculate the weights of the 25 portfolios 
(the market value of the equity of each of the 25 portfolios divided by the total market value of the 25 portfolios) each month in the 1964-1993 period. We define the weights in the market portfolio to be the time-series average of the weights of the 25 portfolios. To be internally consistent in these economies, we sort the market portfolio weights in order to form the weights in the $S M B$ and $H M L$ portfolios. The sort is similar to the sort that FF perform on individual securities to create the returns on their $S M B$ and $H M L$ portfolios. The portfolios' weights are shown in Table 1.

The second step is to calculate a population covariance matrix using a factor model formulation and to use it, together with the portfolios' weights, to construct the population values of the betas and factor loadings. We run the time-series regressions in equation (4) for each portfolio in the 1964-1993 period to generate $\mathbf{B}=\left[\mathbf{b}_{m}, \mathbf{b}_{\text {SMB }}, \mathbf{b}_{H M L}\right]$, an $n \times 3$ matrix containing the factor sensitivities; $\boldsymbol{\Omega}$, a $3 \times 3$ covariance matrix of factor returns; and $\mathbf{D}$, an $n \times n$ diagonal matrix of the residual variances from the regressions. The covariances between residuals for different regressions are set to zero, consistent with the null hypothesis that the factor model completely explains returns, with the exception of idiosyncratic risk. We define the population covariance matrix to be $\mathbf{\Sigma}=\mathbf{B} \boldsymbol{\Omega} \mathbf{B}$ ' $+\mathbf{D}$. Given the covariance matrix, the weights in the market, $S M B$ and $H M L$ portfolios and covariance matrix of factor returns, we calculate the population values of the betas and factor loadings. They are shown in Table 2 .

\section{Tables 1-3 here}

The third and most important step is to construct the population expected return vectors, which guarantee that the market portfolio is either MV-efficient or multifactor-efficient. For illustrative purposes, we focus on two economies—one where the CAPM is true and one where 
the FF model is true with the FF pricing equation parameters set equal to their real-world historic values. The historic FF and CAPM means are shown in Table 3.

We emphasize the importance of working with the population values of the covariance matrix and the vectors of market, $S M B$ and $H M L$ portfolio weights in constructing the CAPM and three-factor model means. Shanken and Zhou (2007), among others, argue that the CAPM is true when betas estimated from time-series regressions are substituted into equation (1). Unfortunately, there is absolutely no guarantee that the positively weighted market portfolio is MV-efficient when these means are combined with the population covariance matrix. For example, we employed the betas estimated from time-series regression equation (2) in equation (1) to construct the CAPM means (with the slope and intercept set equal to 0.5). When we substituted the resulting means together with the population covariance matrix into equation (5) eleven of the tangency portfolio weights were negative. Furthermore, there were no positively weighted portfolios (portfolios where each weight is positive) on the minimum-variance frontier of risky assets. Thus, the market portfolio could not be MV-efficient as required by theory.

Although the cross-sectional and multivariate tests focus primarily on where assets plot relative to the SML, there are other equally important implications of the model. For instance, when the CAPM (FF three-factor model) is true, the market portfolio is MV- (multifactor-) efficient. To give some idea of the values of other population variables when the CAPM is true and when it is false, we plot them in the two economies before examining the power of the crosssectional tests. The upper three panels of Figure 1 show the expected return - standard deviation plot, the expected return - market portfolio beta plot and the expected return - equal-weighted portfolio beta plot when the CAPM is true. The upper left-hand panel shows that the market portfolio is the tangency portfolio on the minimum-variance frontier, and that the equal-weighted 
portfolio has almost the same expected rate of return as the market portfolio. The upper middle panel shows that securities plot on the SML, when expected returns are plotted against market portfolio betas. The upper right-hand panel contains the expected return - equal-weighted portfolio beta plot. The slope of a regression of expected returns on equal-weighted portfolio betas is flatter than the slope of the "security market line."

\section{Figure 1 here}

The lower three panels of Figure 1 show the expected return - standard deviation plot, the expected return - market portfolio beta plot and the expected return - equal-weighted portfolio beta plot when the FF three-factor model pricing equation parameters are equal to their realworld historic values. The lower left-hand panel shows that the minimum-variance frontier is quite distinct from the FF frontier. ${ }^{6}$ The expected return of the tangency portfolio on the minimum-variance frontier is over twice as large as the expected return of the market portfolio, which is the tangency portfolio on the FF frontier. ${ }^{7}$ Moreover, the equal-weighted portfolio's expected return is considerably larger than the expected return of the market portfolio. The lower middle panel shows that the slope of an OLS regression of expected returns on market portfolio betas is negative (as is the slope of a GLS regression). Finally, the lower right-hand panel shows the expected return - equal-weighted portfolio beta plot. Surprisingly, the slopes and intercepts

\footnotetext{
${ }^{5}$ We call the line from the riskfree asset through the equal-weighted portfolio the SML. This is consistent with the empirical work where the line through the proxy for the market portfolio is called the SML.

${ }^{6}$ We generate the minimum-variance and the Fama-French frontiers as special cases of the efficient set mathematics subject to general linear constraints. See Best and Grauer (1990).

${ }^{7}$ Although we do not show it in the paper, if we set the expected excess return on the market portfolio equal to 0.1 and vary the expected returns on the $S M B$ and $H M L$ portfolios in FF pricing equation, there are a number of the values where (simultaneously) the tangency portfolio is inefficient and the market portfolio is multifactor inefficient. The tests provide no hint of this.
} 
of OLS and GLS regressions of expected returns on equal-weighted portfolio betas are closer to the slope and intercept of the "SML" than they are when the CAPM is true.

\section{Cross-sectional and multivariate tests of the CAPM}

Although there are different ways of testing the CAPM, we concentrate on cross-sectional tests and multivariate tests in this paper. Traditional cross-sectional tests are based on some variant of the regression

$$
\bar{r}_{j}-\bar{r}=\gamma_{0}+\gamma_{1} \hat{\beta}_{j}+e_{j},
$$

where $\bar{r}_{j}$ and $\bar{r}$ are time-series average rates of return on risky asset $j$ and the riskfree asset,

respectively, and the $\hat{\beta}_{j}$ 's are estimated from the time-series regression in equation (2). The appeal of this approach is that equation (5) is the empirical analogue of the SML in equation (1). A number of hypotheses are tested in the literature. Research in the 1970's focused on the intercept, testing the null hypothesis that the intercept is equal to zero. If the market is MVefficient, a positive intercept is consistent with a zero-beta version of the CAPM. Then, in an influential study, Fama and French (1992) reject the CAPM because the slope is not statistically significantly different from zero, and variables other than beta, when added to the right-hand side of equation (5), are statistically significantly.

We employ a number of refinements to simple OLS and GLS cross-sectional regressions as well as two multivariate tests in the simulations. First, since returns are cross-sectionally correlated the standard errors from an OLS regression of means on betas are not correct. We employ Fama and MacBeth's (1973) procedure to correct the standard errors. A second way to deal with the problem of cross-sectionally correlated returns is to employ a GLS regression in equation (5). In addition, a potentially important problem is that beta and other right-hand side variables are estimated. Shanken (1992) provides the correction; see Cochrane (2001) as well. 
We employ this correction in the GLS regressions. The GLS regressions lead naturally to Shanken's (1985) multivariate test of the CAPM, which is based on whether the residuals of the GLS cross-sectional regression are equal to zero.

The alternative to the cross-sectional approach is to base tests of the CAPM on time-series regressions. Black, Jensen and Scholes' (1972) test is based on the time-series regression (2). Black, Jensen and Scholes test the null hypothesis that $\alpha_{j}=0$ for each $j$. Gibbons, Ross and Shanken's (1989) multivariate test examines whether the intercepts from equation (2) are jointly equal to zero. The Gibbons, Ross and Shanken test may be interpreted as a multivariate test of the securities' deviations from the SML in mean-beta space or as the difference in the squared Sharpe ratios of a given portfolio and the tangency portfolio in mean-standard deviation space.

To explore the difference in rejection probabilities (power) of the different statistical tests, a simulation is conducted. Two thousand random matrices of size $6,000 \times 25$ are drawn from an $N(0,1)$ distribution. The random matrices are post-multiplied by the transpose of the Choleski decomposition of the returns covariance matrix, converting them to a disturbance matrix $\mathbf{D}$ with rows drawn from an $N(\mathbf{0}, \boldsymbol{\Sigma})$ distribution. An appropriate mean vector $\boldsymbol{\mu}$ is added to generate a matrix of returns. The power of the tests is explored for $\mu_{S M B} \in[-1,1]$ and $\mu_{H M L} \in[-1,1] .^{8}$ Twenty-one evenly spaced points are used in each interval, generating a total of 441 combinations. At each $\left(\mu_{S M B}, \mu_{H M L}\right)$-pair, the population FF mean vector $\boldsymbol{\mu}_{F F}$ is calculated in the manner described in section 2. The transpose of this mean vector is then added to each column of the disturbance matrix to generate a returns matrix $\mathbf{R}$ with rows drawn from $N\left(\boldsymbol{\mu}_{F F}, \boldsymbol{\Sigma}\right)$. The

${ }^{8}$ Arguably some of these values are extreme. But, as we shall see, the Gibbons, Ross and Shanken multivariate test only rejects the CAPM with near certainty when the values are extreme. Moreover, the cross-sectional tests can be sadly deficient even at extreme values. 
returns on the market, $S M B$ and $H M L$ portfolios are calculated by taking the sum of the products of the returns on the 25 assets with their respective portfolio weights.

The statistical tests are performed using the first 120, 360, 600, 1,200, 3,600 and the full 6,000 simulated period returns. An OLS regression, equation (2), is run on each portfolio to generate an intercept, an estimate of the portfolio's beta and a vector of residuals. The FamaMacBeth procedure corrects the standard errors. The tests are counted if they reject the null. Given that the market return is a linear combination of the individual securities, the covariance matrix will be singular. Dropping one asset is required to address this. Using $n-1$ securities, the residual covariance matrix is estimated. This covariance matrix is then used for a GLS regression of mean excess returns on the vector of beta estimates and an intercept for the $n-1$ securities. The slope and intercept tests are again repeated. ${ }^{9}$ The residual covariance matrix and the intercepts from equation (2) are used to conduct Gibbons, Ross and Shanken's multivariate test. Finally, the residual covariance matrix together with the residuals of the GLS regression in equation (5) are used for the Shanken multivariate test. All the tests are also performed at the values for $\mu_{S M B}$ and $\mu_{H M L}$ consistent with the CAPM being true and at their historic values. The 2,000 replications at the $441\left(\mu_{S M B}, \mu_{H M L}\right)$-pairs are then used to plot the power surfaces shown below. The entire process is conducted for both the value-weighted market portfolio and an equal-weighted proxy for the market portfolio.

\footnotetext{
${ }^{9}$ We also estimated the covariance matrix directly from the returns and ran the GLS regression without dropping an asset. The estimates and the rejection probabilities of the slope and intercept were similar to when we dropped an asset and employed the covariance matrix estimated from the residuals.
} 


\section{Results for univariate cross-sectional and multivariate tests of the CAPM}

Space limitations preclude presenting more than a subset of the results. In section 4.1 we focus on the results from the two economies discussed earlier-one where the CAPM is true and one where the FF model is true with the FF pricing equation parameters set equal to their historic values. In section 4.2 we explore what happens when the expected returns of the $S M B$ and $H M L$ portfolios take on a wide range of values in the FF pricing equation. We present plots of a limited set of population values: the slopes, intercepts and R-squares of cross-sectional regressions of expected excess returns on market (and equal-weighted) portfolio betas because the average values of the estimated coefficients in the simulations will approach these population values when the sample size is large. Finally we examine the power of the univariate crosssectional and multivariate tests of the CAPM.

\subsection{Results where the CAPM is true or the FF three-factor model is true with the FF pricing} equation parameters set equal to their historic values

Table 4 examines the power of the tests based on regressions of expected excess returns on market (and equal-weighted) portfolio betas, when the CAPM is true and when the FF threefactor model is true with the FF pricing equation parameters set equal to their historic values. In each of 2000 replications, the size of the test is 5\%. The null hypothesis is that the intercept (slope) is equal to zero. The alternative is that the intercept (slope) is not equal to zero. When the CAPM is true, we expect the null that the intercept is zero to be rejected $5 \%$ of the time; and the null that the slope is zero to be rejected well over 5\% of the time. The first row of each panel contains the population parameters for the intercept, slope and R-square. Then, for each sample size, the first row shows the average values of the intercept, slope and R-square. The second row shows the percentage of times the null hypotheses are rejected at the 5\%-level. 
It is clear from Table 4 that the well-known problem of measurement errors in beta, which causes the estimated slope to be closer to zero than the true slope is, is important whether the CAPM is true or false. With 120 observations, the average values of the intercepts and slopes are far from their population values. (The tests based on equal-weighted portfolio betas when the CAPM is true provide an exception.) With 360 observations, the average values of the coefficients begin to approach their population values.

\section{Table 4 here}

In Panel A the CAPM is true. When the CAPM is true and market portfolio betas are employed in the tests, there are three central results. First, the tests of whether the slope is equal to zero lack power. Even under ideal conditions, the hypothesis that the slope is zero is rejected only $9 \%$ of the time with 360 observations! It is only with 3,600 observations (300 years of monthly data) that the hypothesis that the slope is zero is rejected over $50 \%$ of the time. This suggests that the claim the CAPM is dead-because empirical evidence indicates the slope is indistinguishable from zero-may be greatly exaggerated. Second, tests of whether intercept is equal to zero are informative. The rejection percentages settle down to the 5\%-level with 360 observations. Third, the average values of the sample R-squares are surprisingly low given that the population R-square is equal to one.

Equally important, the results differ with the use of the market and equal-weighted portfolio betas-even though the population correlation between the returns of these two portfolios exceeds 0.9. Specifically, when equal-weighted portfolio betas are employed in the tests, the results provide incorrect indications that the CAPM should be rejected. But it takes 3,600 observations for the rejection percentage of the hypothesis that the intercept is equal to zero to exceed $40 \%$. 
In Panel B the FF three-factor model is true with the FF pricing equation parameters set to their historic values. When market portfolio betas are employed in tests of the CAPM, the intercept tests correctly reject it. (But the power is low. With 360 observations, rejections at the $5 \%$-level occur less than $50 \%$ of the time.) Moreover, there is little evidence that the slope is different from zero. Hence, both the slope and intercept test correctly indicate that the CAPM is false. On the other hand, with equal-weighted portfolio betas, rejections of the null hypothesis that the intercept (slope) is zero are low (high), both of which incorrectly indicate that the CAPM is true. Ironically, if equal-weighted portfolio betas are used in the tests in these two economies, the odds are that the CAPM will appear to be false when it is true and true when it is false.

\subsection{Results for cross-sectional tests based on a broad range of $\left(\mu_{S M B}, \mu_{H M L}\right)$-values}

In this section we first examine the population values of the slopes, intercepts and R-squares (and the average value of the sample R-squares) from cross-sectional regressions of expected excess returns on betas because the average values of the estimated coefficients in the simulations will approach these population values when the sample size is large. Then we examine the power of the univariate cross-sectional and multivariate tests of the CAPM as the parameters in the FF pricing equation vary. More specifically, we vary the expected returns of the $S M B$ and $H M L$ portfolios in the interval from $-1 \%$ to $+1 \%$ per month, holding the expected excess return on the market and the riskfree rate constant at $0.5 \%$ per month in equation (2). In Figures 2-6 the point labeled $C A P M$, where $\mu_{S M B}=0.054 \%$ and $\mu_{H M L}=-0.124 \%$, indicates the point where the CAPM is true. The point labeled historic, where $\mu_{S M B}=0.417 \%$ and $\mu_{H M L}=0.533 \%$, indicates the point where the FF pricing equation parameters are set to their historic values. A well-behaved test of the CAPM should indicate that the CAPM is incorrect as 
we move away from the CAPM point in the $\left(\mu_{S M B}, \mu_{H M L}\right)$-grid, i.e., the power surface should be a bowl with the bottom of the bowl at the CAPM point.

Figure 2 contains four plots that display the population contours of the intercepts (dashed lines) overlaid on the contours of the slopes (solid lines) from regressions of expected excess returns on betas. The upper-left (upper-right) plot contains the results for OLS (GLS) regressions of expected excess returns on market portfolio betas. The lower-left (lower-right) plot contains the results for OLS (GLS) regressions of expected excess returns on equal-weighted portfolio betas. The plots contain a wealth of information. Three results are crucial. First, there are points in the plots where the CAPM is patently false. Yet the population slopes and intercepts have exactly the same values as when the CAPM is true. Second, the directions of the slope and intercept contours differ from plot to plot. ${ }^{10}$ Third, there are points in the plots characterized by large positive (negative) slopes (intercepts), and vice versa. This suggests we may reach different conclusions about whether the CAPM holds if we test the hypothesis that the intercept (slope) is equal to zero, or if we employ market (equal-weighted portfolio) betas in the test.

\section{Figure 2 here}

The plots in Figure 3 confirm these suspicions. Figure 3 contains power surfaces for tests that the intercept (slope) of OLS regressions of expected excess returns on betas is equal to zero. The Fama-MacBeth procedure corrects the standard errors of the OLS estimates. The rejection probabilities are based on tests with a size of 5\%, 600 observations and 2,000 replications. The left-hand (right-hand) plots contain results for intercept (slope) tests. The upper (lower) plots employ market (equal-weighted) portfolio betas. Before viewing the power surfaces, note that a

\footnotetext{
10 The intercept and slope contours are parallel in GLS regressions of excess expected returns on market portfolio betas because the slope plus the intercept sum to the expected excess return on the market, which in the simulations is equal to 1.0.
} 
test of whether the intercept is equal to zero provides a direct test of the CAPM. Ideally, the probability of rejecting a false null should increase the more false the model is, regardless of how the null is made false. In the present two dimensional $\left(\mu_{S M B}, \mu_{H M L}\right)$ context, the power surface should be a bowl with the bottom of the bowl centered at the CAPM point. A test of whether the slope is equal to zero does not provide a direct or an unambiguous test of the CAPM. However, it should reject the hypothesis that the slope is zero with high probability at the CAPM point. Unfortunately, as we have already seen, it does not. In addition, if the hypothesis that the slope is zero is rejected it does not mean that the CAPM is correct-the slope could be negative or it could be positive and too steep. For example, at the lower-right-hand corner of the upper-left-hand population contour in Figure 2, the slope is in excess of 3, and statistically different from zero as seen in Figure 3. But, in results not reported in tables or figures, we verified that at this point the tangency portfolio's population expected return is $5.78 \%$, which is nowhere near the market portfolio's expected return of $1 \%$.

The power surfaces in Figure 3 are characterized by deep valleys, where the probability of rejecting the hypothesis that the slope or intercept is equal to zero is low. The directions of the valleys in the power surfaces for the slope and intercept differ marginally. The direction of the valleys in the power surfaces based on market and equal-weighted portfolio betas differ dramatically. This causes two problems. First, low rejection probabilities for the intercept mean we cannot reject the CAPM. FF interpret low rejection probabilities for the slope as evidence against the CAPM. Thus, the slope and intercept tests (from either market or equal-weighted portfolio betas) provide contradictory evidence about whether or not the CAPM is true. Second, there are points in the $\left(\mu_{S M B}, \mu_{H M L}\right)$ - plane where the hypothesis that the intercept is zero is rejected about $5 \%$ of the time with market portfolio betas and $100 \%$ of the time with equal- 
weighted portfolio betas. And, there are other points where the hypothesis that the intercept is zero is rejected about $5 \%$ of the time with equal-weighted portfolio betas and $100 \%$ of the time with market portfolio betas.

\section{Figure 3 here}

When the CAPM is true, theory says the expected return - beta plot is exactly linear. Therefore, one might expect that the R-square from regressions of expected excess returns on market betas would provide additional insight into whether the CAPM is true or false. But Kandel and Stambaugh's (1995) analysis of the OLS R-square cautions that it might not. Figure 4 shows the population OLS and GLS R-squares and the average values of the R-squares based on tests with 600 observations and 2,000 replications. The figure shows that the population Rsquares are equal to one at the CAPM point. The R-square values drop precipitously to the order of 0.1 near the CAPM point. Yet, the R-squares are well in excess of 0.5 for combinations of $\left(\mu_{S M B}, \mu_{H M L}\right)$ where one is large and the other is small and the slope of the regression of means on betas is well above either \pm 2 . Surprisingly, the average values of the R-square are nowhere near their population counterparts. The low average values of the sample R-squares, particularly at and near the CAPM point, suggest that an examination of the sample R-square will provide little insight into whether the CAPM is true or false.

\section{Figure 4 here}

\subsection{Results for the multivariate tests based on a broad range of $\left(\mu_{S M B}, \mu_{H M L}\right)$-values}

Figure 5 shows the rejection probabilities for Gibbons, Ross and Shanken's multivariate test of the efficiency of the market portfolio and Shanken's multivariate cross-sectional test. The probabilities are based on tests with a size of 5\%, 2,000 replications and 120, 360 or 600 observations. In contrast to the cross-sectional regressions, the Gibbons, Ross and Shanken 
multivariate test is relatively well-behaved. With 360 and 600 observations, the power surface of the Gibbons, Ross and Shanken test is almost symmetric. Nonetheless, with 120 observations the power is low except in the cases where $\mu_{S M B}$ and $\mu_{H M L}$ simultaneously take on their extreme values. For the most part, Gibbons, Ross and Shanken's multivariate test exhibits greater power than Shanken's multivariate cross-sectional test (which is characterized by a deep valley indicating low power) and the tests based on cross-sectional regressions of means on betas.

\section{Figure 5 here}

Figure 6 compares the rejection probabilities for three multivariate tests—-the Gibbons, Ross and Shanken test, the conventional Shanken test, where the cross-sectional GLS regression is fitted with an intercept, and a Shanken-type test, where the cross-sectional GLS regression is fitted without an intercept. The efficiency of the market portfolio is tested in the left-hand panels. The efficiency of an equal-weighted proxy for the market portfolio is tested in the right-hand panels. The probabilities are based on tests with a size of 5\%, 600 observations and 2,000 replications. The power surfaces of the Gibbons, Ross and Shanken test are quite similar. This result is consistent with Shanken's (1987) and Kandel and Stambaugh's (1987) analysis, which suggest that if the correlation between the returns on the true market and a proxy for it are high, the rejection probabilities will be similar. The symmetric power surfaces of the Gibbons, Ross and Shanken test differ dramatically from the power surfaces of Shanken's multivariate crosssectional test, which are characterized by deep valleys that are orthogonal to each other. The importance of fitting a cross-sectional regression with or without an intercept is underscored when we fit the GLS regression without an intercept and construct a Shanken-type multivariate test. The resulting power surfaces are very close—but not identical—to the symmetric power 
surfaces of the Gibbons, Ross and Shanken test. Moreover, the Shanken test without an intercept is uniformly more powerful than the Shanken test with an intercept.

\section{Figure 6 here}

\section{Tests of whether beta alone explains the cross-section of expected returns}

In this section we highlight the problems associated with cross-sectional tests of the CAPM when the right-hand variables are factor loadings. Three facts assist in understanding the results. First, in an appendix available from the authors, we show that in a GLS cross-sectional regression of expected excess returns on factor loadings estimated jointly from a time-series regression, the intercept and the slope of the market factor loading sum to the expected excess return on the market portfolio and the slope of any zero-weight portfolio factor loading is equal to the factor portfolio's expected return. Second, Table 2 shows that the spread of the $S M B$ and $H M L$ factors is much larger than the spread in the market factor. Hence, in cross-sectional tests employing these factors the slope of the market factor will appear to be less important than the slopes of the $S M B$ and $H M L$ factors. Third, Chen, Roll and Ross (1986) note that a test of the CAPM should employ betas from univariate time-series regressions and the other factor loadings from multivariate time-series regressions. Hence, if the right-hand variables in the crosssectional regression are estimated from the multivariate regression equation (4) we are testing the FF three-factor model and not the CAPM.

The results in panels A-C show that even slight modifications of the cross-sectional testing equation, or deviations in the way in which standard errors and $t$-tests are calculated, can make the CAPM appear to be false when it is true. In panel A the factor loadings of the market, $S M B$ and $H M L$ portfolios are estimated from the multivariate regression equation (4). If we mistakenly regard this as a test of the CAPM we have weak evidence against the model. But it takes 3,600 
observations to see that the risk premiums for the $S M B$ and $H M L$ portfolios are statistically significantly different from zero. If we correctly regard it as a test of the FF three-factor model, the results are similar to the univariate cross-sectional CAPM test results. That is, the rejection percentages for the intercept are at the 5\%-level with 360 observations as they should be. But tests of whether the slopes are equal to zero lack power.

\section{Table 5 here}

In panels $\mathrm{B}$ and $\mathrm{C}$ the market betas are estimated from the univariate regression equation (2) and the factor loadings for the $S M B$ and $H M L$ portfolios are estimated from multivariate regressions of asset returns on $S M B$ and $H M L$ returns. As noted, these tests are best interpreted as tests whose null hypothesis is the CAPM. In panel B the correct market portfolio betas and a GLS cross-sectional regression are employed in the tests. With 360 observations there is fairly strong evidence against the CAPM, the coefficient for the $S M B(H M L)$ factor is statistically significant $38 \%$ (21\%) of the time. In other words, something other than beta appears to explain the cross-section of returns, even though the CAPM is absolutely correct! However, when Shanken's correction to the $t$-statistics is employed in panel C, the tests correctly reject the hypotheses that slopes of the $S M B$ and $H M L$ factors are different from zero 5\% of the time.

In panel D the CAPM is false with the FF three-factor pricing equation parameters set to their historic values. Recall that in this case the population expected excess return on the market portfolio and the expected return on the $S M B$ and $H M L$ portfolios are $0.5,0.42$ and 0.53 , respectively. When the factor loadings of the market, $S M B$ and $H M L$ portfolios are estimated from the multivariate regression equation (4) we are testing the three-factor model. Tests of the intercept and the slopes associated with the $S M B$ and $H M L$ loadings support the model. But, with $360(3,600)$ observations the average value of the estimate of the market slope is $0.24(0.45)$, 
and the slope is statistically different from zero only $7 \%$ (33\%) of the time. When beta is estimated separately from the factor loadings of the $S M B$ and $H M L$ portfolios we are testing the CAPM. In this case something other than beta explains the cross-section of expected returns. But, it should be noted that the $S M B$ and $H M L$ slopes are statistically significant from zero more often than the market slope, the average values of the slope coefficients are not equal to their population values, and the intercept and slope of the market factor do not sum to the expected excess return on the market.

\section{Summary and concluding comments}

We construct a large number of FF three-factor economies where the CAPM is a special case. This provides the first opportunity to examine whether cross-sectional and multivariate tests of the CAPM have the power to reject it when all the implications of the CAPM are true. In addition, it provides the first opportunity to examine the power of the tests when an alternative asset pricing model determines prices when the CAPM is false. An examination of the population intercepts, slopes and R-squares from cross-sectional regressions of expected returns on betas indicates that all three are unreliable indicators of whether CAPM holds. When the CAPM is palpably false, the population slopes and intercepts can take on the same values as they do when it is correct. Moreover, the population R-square is much lower when the CAPM is almost true than when it is clearly false.

Simulation analysis of the power of the cross-sectional tests expands on and reinforces the analysis based on population values. To be consistent with the single-period framework, it is assumed that sample drawings are taken instantaneously from a fixed joint normal return distribution. There are no problems with stationarities of any kind, i.e., in returns, betas, or weights in the market, the $S M B$ and $H M L$ portfolio. The tests are sadly deficient under this 
simplest of possible scenarios. First, the cross-sectional tests have virtually no power to reject the hypothesis that the slope is equal to zero when the CAPM is true. There are also problems with tests of whether the slope is zero when the CAPM is false because a positive slope that is statistically significantly different from zero does not necessarily mean the CAPM is true. Second, the power surfaces for tests of the hypothesis that the intercept is zero are scarred by deep valleys where the CAPM cannot be rejected, even though in some cases it is patently false. Third, tests of whether the slope or intercept of the regression are equal to zero can lead to diametrically opposite inferences. In one instance, tests of the hypothesis that the slope is equal to zero are rejected in only $10 \%$ of 2,000 replications, which might lead some to conclude that the CAPM is dead. Concurrently tests of the hypothesis that the intercept is equal to zero are rejected 9\% of the time, which might lead some to conclude that the CAPM is alive and well. ${ }^{11}$ Fourth, the average values of the sample R-squares are much lower than the population values, especially when the CAPM is true. ${ }^{12}$

Employing equal-weighted portfolio betas in the cross-sectional tests exacerbates the problems even though the population correlation between the returns of the equal-weighted and market portfolio returns exceeds 0.9. Tests of whether the intercept (slope) is equal to zero can differ dramatically depending on whether we use market or equal-weighted portfolio betas. This result, corroborated by Connolly and Rendleman (2007), reinforces and strengthens Roll's (1977) critique: even when all the assets in an economy are observed, employing a proxy for the true

\footnotetext{
${ }^{11}$ To add fat to the fire, at this point the Gibbons, Ross and Shanken multivariate test rejects the hypothesis that the market portfolio is efficient in over $93 \%$ of the 2,000 replications.

${ }^{12}$ As if the problems associated with the values of the population and sample R-squares in crosssectional tests of a single-factor model are not bad enough, Lewellen, Nagel and Shanken (2006) show that in size and book-to-market equity datasets it is easy to find high cross-sectional Rsquares for almost any multifactor model.
} 
market portfolio can lead one to draw wrong conclusions. Perhaps surprisingly, these clear and unambiguous results generated under ideal conditions are not apparent in real world datasets. For example, the empirical evidence in Stambaugh (1982) and Grauer (1981) indicates different proxies for the market portfolio have little effect on the outcome of tests of the CAPM and other asset pricing models.

Tests of whether beta alone explains the cross-section of expected returns work better. When the CAPM is false, the coefficients on the $S M B$ and $H M L$ factor loadings are often statistically significantly different from zero. There are caveats, however, concerning whether or not market betas are estimated separately from the other factor loadings. And, even seemingly slight modifications of the testing equations of this sort, or slight deviations in the way in which standard errors and $t$-tests are calculated, can make the CAPM appear to be false when it is true.

Many of the problems with the cross-sectional tests may be traced to whether or not an intercept term is included in the cross-sectional regressions. (Arguably, Shanken's multivariate test provides the most graphic illustration. The power surface for Shanken's multivariate test, which is based on a GLS regression with an intercept, contains a deep valley where the power is low. On the other hand, a Shanken-type multivariate test, which is based on a GLS regression without an intercept, exhibits a symmetric power surface.) To be specific, in an appendix available from the authors, we show that in a GLS regression of expected returns on factor loadings, the intercept and the slope on the market factor loading sum to the expected return on the market, while the slope on any zero-weight portfolio factor loading is equal to the factor portfolio's expected return. (The traditional CAPM result is a special case, see Roll (1985).) In a GLS regression of expected returns on factor loadings that does not include an intercept, the 
slopes are equal to the factor portfolios' expected returns. ${ }^{13}$ These results help explain the empirical results. If the cross-sectional regression is run with an intercept, then all included portfolios that have unit-weights (i.e., the market) will "share" their contribution with the intercept term. In contrast, all portfolios that have zero-weight (i.e., $S M L$ and $H M L$ ) will have coefficients that are immune to the inclusion of an intercept. As a result, theoretical predictions about coefficient values of zero-weight portfolios will be found to hold in the model with an intercept, while those for unit-weight portfolios will almost certainly not hold exactly and are likely to not hold statistically.

Gibbons, Ross and Shanken's multivariate test performs much better. Although the power of the test is low with 120 observations, it improves considerably with 360 or 600 observations. It is clear then that the multivariate test can reject the CAPM in the FF three-factor settings. This result is noteworthy in that it challenges MacKinlay's (1995) view that multifactor models do not explain deviations from the CAPM. In addition, consistent with the arguments in Kandel and Stambaugh (1987) and Shanken (1987), the results of the multivariate test are not as strongly influenced by the choice of a proxy portfolio that is highly correlated with the market.

In closing we note that grouped datasets used to test the CAPM do not produce a wide range of market betas, a problem that is inherent in our simulated economies as well, see Table 2. Hence, in regressions of average excess returns on betas, tests of whether the slope of the market factor is equal to zero are bound to lack power. In a companion paper, Grauer and Janmaat (2008), we show how to increase the spread in betas using the returns from zero-weight portfolios in cross-sectional tests of the CAPM and FF three-factor model. Simulations show this

\footnotetext{
${ }^{13}$ In a slightly different context, Schwert (2000) and Simin (2006) make the case for suppressing the intercept in regressions used for predicting returns.
} 
increases the power of the tests substantially. In real world datasets the results are even more

pronounced. Although cross-sectional tests provide little or no support for either the CAPM or FF three-factor model in fourteen standard datasets, they provide strong support for the CAPM in three sets of fourteen transformed zero-weight portfolio datasets.

\section{Acknowledgements}

Financial support from the Social Sciences and Humanities Research Council of Canada is greatly appreciated, as is the assistance of Christopher Fong. The paper was presented at Simon Fraser University, the University of British Columbia, the University of Toronto, the University of Washington, the 5th Annual Hawaii International Conference on Business in Honolulu, the Northern Finance Association meetings in Vancouver, and the Canadian Econometric Study Group Conference in Vancouver. We thank the seminar participants, Reo Audette, George Blazenko, Rene Garcia, Lawrence He, Peter Klein, Ray Koopman, Paul Malatesta, Angelo Melino, Andrey Pavlov, Ed Rice, Andy Siegel, and especially two anonymous referees, Raymond Kan and Daniel Smith for most helpful discussions and comments.

\section{References}

Affleck-Graves, J., McDonald, B., 1990. Multivariate tests of asset pricing: The comparative power of alternative statistics. Journal of Financial and Quantitative Analysis 25, 163-185.

Amsler, C.E., Schmidt, P., 1985. A Monte Carlo investigation of the accuracy of multivariate CAPM tests. Journal of Financial Economics 14, 359-375.

Best, M.J., Grauer, R.R., 1985. Capital asset pricing compatible with observed market value weights. Journal of Finance 40, 85-103.

Best, M.J., Grauer, R.R., 1990. The efficient set mathematics when mean-variance problems are subject to general linear constraints. Journal of Economics and Business 42, 105-120.

Black, F., 1972. Capital market equilibrium with restricted borrowing. Journal of Business 45, 444-455. 
Black, F., Jensen, M.C., Scholes, M., 1972. The capital asset pricing model: Some empirical evidence. In: Jensen, M.C., (Ed.), Studies in the Theory of Capital Markets, Praeger Publishers: New York.

Blume, M.E., Friend, I., 1973. A new look at the capital asset pricing model. Journal of Finance 28, 19-33.

Campbell, J.Y., Lo, A.W., MacKinlay, A.C., 1997. The Econometrics of Financial Markets. Princeton University Press: Princeton, New Jersey.

Chen, R., Kan, R., 2006. Finite sample analysis of two-pass cross-sectional regressions. Working paper University of Toronto.

Chen, N., Roll R., Ross, S.A. 1986. Economic forces and the stock market. Journal of Business 56, 383-403.

Cochrane, J.H., 2001. Asset Pricing. Princeton University Press: Princeton, New Jersey.

Connolly, R.A., Rendleman Jr., R.J., 2007. A simulation-based assessment of cross-sectional CAPM testing methodology. Working paper University of North Carolina.

Fama, E.F., 1976. Foundations of Finance. Basic Books: New York.

Fama, E.F., 1996. Multifactor portfolio efficiency and multifactor asset pricing. Journal of Financial and Quantitative Analysis 31, 441-465.

Fama, E.F., French, K.R., 1992. The cross-section of expected stock returns. Journal of Finance 47, 427-466.

Fama, E.F., French, K.R., 1993. Common risk factors in the returns on bonds and stocks. Journal of Financial Economics 33, 3-56.

Fama, E.F., French, K.R., 1996. Multifactor explanations of asset pricing anomalies. Journal of Finance 51, 55-84.

Fama, E.F., MacBeth, J.D., 1973. Risk, return and equilibrium: Empirical tests. Journal of Political Economy 81, 607-636.

Ferson, W., Sarkissian, S., Simin, T., 2008. Asset pricing models with conditional betas and alphas: The effects of data snooping and spurious regression. Journal of Financial and Quantitative Analysis 33, 331-354.

Gibbons, M.R., Ross, S.A., Shanken, J. 1989. A test of the efficiency of a given portfolio. Econometrica 57, 1121-1152.

Grauer, R.R., 1981. Investment policy implications of the capital asset pricing model. Journal of Finance 36, 127-141.

Grauer, R.R., 1999. On the cross-sectional relation between expected returns, betas, and size. Journal of Finance 54, 773-789.

Grauer, R.R., Janmaat, J.A., 2004. The unintended consequences of grouping in tests of asset pricing models. Journal of Banking and Finance 28, 2889-2914.

Grauer, R.R., Janmaat, J.A. 2008. Cross-sectional tests of the CAPM and Fama-French threefactor model. Working paper, Simon Fraser University. 
Jobson, J.D., Korkie, B., 1982. Potential performance and tests of portfolio efficiency. Journal of Financial Economics 10, 433-466.

Jobson, J.D., Korkie, B., 1985. Some tests of linear asset pricing with multivariate normality. Canadian Journal of Administrative Sciences 2, 114-138.

Kan, R., Zhang, C., 1999. Two-pass tests of asset pricing models with useless factors. Journal of Finance 54, 203-235.

Kandel, S., Stambaugh, R.F., 1987. On correlations and inferences about mean-variance efficiency. Journal of Financial Economics 18, 61-90.

Kandel, S., Stambaugh, R.F., 1995. Portfolio inefficiency and the cross-section of mean returns. Journal of Finance 50, 157-184.

Kothari, S.P., Shanken, J., Sloan, R., 1995. Another look at the cross-section of expected stock returns. Journal of Finance 50, 185-224.

Lewellen, J., Nagel, S., Shanken, J., 2006. A skeptical appraisal of asset pricing tests. NBER Working Paper 12360.

Lintner, J., 1965. The valuation of risk assets and the selection of risky investments in stock portfolios and capital budgets. Review of Economics and Statistics 47, 13-47.

Lo, A.W., MacKinlay, A.C., 1990. Data-snooping biases in tests of financial asset pricing models. Review of Financial Studies 3, 431-467.

MacKinlay, A.C., 1987. On multivariate tests of the CAPM. Journal of Financial Economics 18, 341-371.

MacKinlay, A.C., 1995, Multifactor models do not explain deviations from the CAPM. Journal of Financial Economics 38, 3-28.

Merton, R.C., 1973. An intertemporal capital asset pricing model. Econometrica 41, 867-887.

Miller, M., Scholes, M., 1972. Rates of return in relation to risk: A re-examination of some recent findings. In: Jensen, M.C., (Ed.): Studies in the Theory of Capital Markets. Praeger Publishers: New York.

Roll, R., 1977. A critique of the asset pricing theory tests; part I: On past and potential testability of the theory. Journal of Financial Economics 4, 129-176.

Roll, R., 1985. A note on the geometry of Shanken's CRT T2 test for mean/variance efficiency. Journal of Financial Economics 14, 349-357.

Roll, R., Ross, S.A., 1994. On the cross-sectional relation between expected returns and betas. Journal of Finance 49, 101-121.

Rosenberg, B., Reid, K., Lanstein, R., 1985. Persuasive evidence of market inefficiency. Journal of Portfolio Management 11, 9-17.

Schwert, G.W., 2000, Hostility in takeovers: In the eyes of the beholder? Journal of Finance 55, 2599-2640.

Shanken, J., 1985. Multivariate tests of the zero-beta CAPM. Journal of Financial Economics 14, 327-348. 
Shanken, J., 1987. Multivariate proxies and asset pricing relations: Living with the Roll critique. Journal of Financial Economics 18, 91-110.

Shanken, J., 1992. On estimation of beta pricing models. Review of Financial Studies 5, 1-34.

Shanken, J., Zhou, G., 2007. Estimating and testing beta pricing models: alternative methods and their performance in simulations. Journal of Financial Economics 84, 40-86.

Sharpe, W.F., 1964. Capital asset prices: A theory of market equilibrium under conditions of risk. Journal of Finance 19, 425-442.

Simin, T., 2008. The (poor) predictive performance of asset pricing models. Journal of Financial and Quantitative Analysis 43, 355-380.

Stambaugh, R.F., 1982. On the exclusion of assets from tests of the two-parameter model: A sensitivity analysis. Journal of Financial Economics 10, 237-286.

\section{Appendix}

\section{A.1 The effect of suppressing the intercept in GLS regressions of means on factor loadings}

We show two main results in this section of the appendix. First, in a GLS regression of expected returns on factor loadings, the intercept and the slope on the market factor loading sum to the expected return on the market, while the slope on any zero-weight portfolio factor loading is equal to the factor portfolio's expected return. In a GLS regression of expected returns on factor loadings that does not include an intercept, the slopes are equal to the factor portfolios' expected returns. These results help explain the empirical results. Second, when a GLS regression includes factor loadings from zero-weight portfolios only, the slope of the zeroweight portfolio factor loadings are equal to the factor portfolios' expected returns, whether or not the regression includes an intercept. But, suppressing the intercept dramatically changes the slope coefficients in an OLS regression.

Consider the regression $\mathbf{y}=\mathbf{W A}+\mathbf{e}$, where $\mathbf{y}$ is an $n$-vector containing the dependent variable, $\mathbf{W}$ is an $n \times k$ matrix containing $n$ observations on the $k$ independent variables, $\mathbf{A}$ is a $k$-vector of coefficients and $\mathbf{e}$ is an $n$-vector containing the error terms. It is assumed that $E(\mathbf{e})=\mathbf{0}$ and $E\left(\mathbf{e e}^{\prime}\right)=\boldsymbol{\Sigma}$, where $E($.$) is the expectations operator. The GLS coefficient vector is$ 


$$
\mathbf{A}=\left(\mathbf{W}^{\prime} \boldsymbol{\Sigma}^{-1} \mathbf{W}\right)^{-1} \mathbf{W}^{\prime} \boldsymbol{\Sigma}^{-1} \mathbf{y}
$$

We examine the case where we regress expected returns $\boldsymbol{\mu}$ on factor sensitivities, say, $\mathbf{B}=\boldsymbol{\Sigma} \mathbf{X} \boldsymbol{\Omega}^{-1}=\left[\mathbf{b}_{m}, \mathbf{b}_{S M B}, \mathbf{b}_{H M L}\right]$ where $\boldsymbol{\Omega}$ is the covariance matrix of the factor returns and $\mathbf{X}=\left[\mathbf{x}_{m}, \mathbf{x}_{\text {SMB }}, \mathbf{x}_{\text {HML }}\right]$. (The expected returns need not necessarily be CAPM or FF expected returns nor do the portfolios have to be the market, $S M B$ and $H M L$ portfolios-they can be any $n$ portfolios, where some of the portfolios' weights sum to one and the weights of others sum to zero.) If we run the regression with an intercept, $\mathbf{W}=\left[\begin{array}{ll}\mathbf{l} & \mathbf{\Sigma X \boldsymbol { \Omega } ^ { - 1 }}\end{array}\right]$ and

$$
\mathbf{A}=\left[\begin{array}{cc}
c & \mathbf{l}^{\prime} \mathbf{X} \boldsymbol{\Omega}^{-1} \\
\boldsymbol{\Omega}^{-1} \mathbf{X}^{\prime} \mathbf{\imath} & \boldsymbol{\Omega}^{-1}
\end{array}\right]^{-1}\left[\begin{array}{c}
a \\
\boldsymbol{\Omega}^{-1} \mathbf{X}^{\prime} \boldsymbol{\mu}
\end{array}\right]
$$

where $a=\mathbf{\imath}^{\prime} \boldsymbol{\Sigma}^{-1} \boldsymbol{\mu}$ and $c=\mathbf{\imath}^{\prime} \boldsymbol{\Sigma}^{-1} \mathbf{l}$. To find $\left(\mathbf{W}^{\prime} \boldsymbol{\Sigma}^{-1} \mathbf{W}\right)^{-1}$ we employ a partitioned matrix $\mathbf{B}$ and its inverse $\mathbf{B}^{-1}$

$$
\mathbf{B}=\left[\begin{array}{ll}
\mathbf{B}_{11} & \mathbf{B}_{12} \\
\mathbf{B}_{21} & \mathbf{B}_{22}
\end{array}\right] \text { and } \mathbf{B}^{-1}=\left[\begin{array}{cc}
\mathbf{C}_{11} & -\mathbf{B}_{11}^{-1} \mathbf{B}_{12} \mathbf{C}_{22} \\
-\mathbf{B}_{22}^{-1} \mathbf{B}_{21} \mathbf{C}_{11} & \mathbf{C}_{22}
\end{array}\right] \text {, }
$$

where

$$
\mathbf{C}_{11}=\left(\mathbf{B}_{11}-\mathbf{B}_{12} \mathbf{B}_{22}^{-1} \mathbf{B}_{21}\right)^{-1} \text { and } \mathbf{C}_{22}=\left(\mathbf{B}_{22}-\mathbf{B}_{21} \mathbf{B}_{11}^{-1} \mathbf{B}_{12}\right)^{-1}
$$

Making the relevant substitutions from equation (A.11) into equation (A.12) and simplifying gives

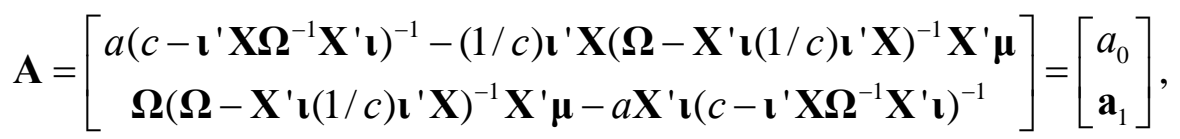

where $a_{0}$ is the intercept and $\mathbf{a}_{1}$ is a 3-vector containing the slope coefficients on the market, $S M B$ and $H M L$ portfolios. 
To sum the intercept plus the slope on the market factor loading, it is convenient to form the sum $a_{0} \mathbf{X}^{\prime} \mathbf{\imath}+\mathbf{a}_{1}$, which relies on the fact that $\mathbf{X}^{\prime} \mathbf{\imath}=\left[\begin{array}{lll}1 & 0 & 0\end{array}\right]^{\prime}$. (In words, the intercept is a scalar, so we add the intercept to the slope of the market factor loading and zeros to the slopes of the factor loadings on $S M B$ and $H M L$.) Multiplying the intercept by $\mathbf{X}^{\prime} \mathbf{\imath}$ yields

$$
a \mathbf{X}^{\prime} \mathbf{\imath}\left(c-\mathbf{\imath}^{\prime} \mathbf{X} \boldsymbol{\Omega}^{-1} \mathbf{X}^{\prime} \mathbf{\imath}\right)^{-1}-(1 / c) \mathbf{X}^{\prime} \mathbf{u} \mathbf{u}^{\prime} \mathbf{X}\left(\boldsymbol{\Omega}-\mathbf{X}^{\prime} \mathbf{\imath}(1 / c) \mathbf{\imath}^{\prime} \mathbf{X}\right)^{-1} \mathbf{X}^{\prime} \boldsymbol{\mu} .
$$

When we add the slope coefficients from equation (A.13) to equation (A.14) simplify and cancel, the sum is

$$
\mathbf{X}^{\prime} \boldsymbol{\mu}=\left[\begin{array}{lll}
\mu_{m} & \mu_{S M B} & \mu_{H M L}
\end{array}\right]^{\prime} .
$$

Thus, the sum of the intercept plus the slope of the market factor loading is equal to the expected return on the market, and the slopes of the zero-weight portfolio factor loadings are equal to the factors' expected returns.

The traditional CAPM result is a special case where $\mathbf{W}=\left[\begin{array}{lll}\mathbf{l} & \boldsymbol{\Sigma} \mathbf{x}_{m} / \sigma_{m}^{2}\end{array}\right]=\left[\begin{array}{ll}\mathbf{l} & \boldsymbol{\beta}_{m}\end{array}\right]$, i.e., $\mathbf{X}=\mathbf{x}_{m}$ and $\boldsymbol{\Omega}=\sigma_{m}^{2}$. As Roll (1985) first showed

$$
\mathbf{A}^{\prime}=\left[\begin{array}{ll}
\frac{a \sigma_{m}^{2}-\mu_{m}}{c \sigma_{m}^{2}-1} & \frac{\left(c \mu_{m}-a\right) \sigma_{m}^{2}}{c \sigma_{m}^{2}-1}
\end{array}\right]=\left[\begin{array}{ll}
a_{0} & a_{1}
\end{array}\right]
$$

The intercept $a_{0}$ is a zero-beta rate and $a_{1}=\mu_{m}-a_{0}$, i.e., the slope is the expected return on the market less the zero-beta rate. It is easily verified that the sum of the slope and the intercept is the expected return on the market.

If we run a cross-sectional GLS regression of expected returns on factor loadings without an intercept, $\mathbf{W}=\mathbf{\Sigma} \mathbf{X} \mathbf{\Omega}^{-1}$ and

$$
\mathbf{A}=\left(\boldsymbol{\Omega}^{-1} \mathbf{X}^{\prime} \boldsymbol{\Sigma} \boldsymbol{\Sigma}^{-1} \mathbf{X} \boldsymbol{\Sigma} \boldsymbol{\Omega}^{-1}\right)^{-1} \boldsymbol{\Omega}^{-1} \mathbf{X}^{\prime} \boldsymbol{\Sigma} \boldsymbol{\Sigma}^{-1} \boldsymbol{\mu}=\left(\boldsymbol{\Omega}^{-1} \boldsymbol{\Omega} \boldsymbol{\Omega}^{-1}\right)^{-1} \boldsymbol{\Omega}^{-1} \mathbf{X}^{\prime} \boldsymbol{\mu}=\mathbf{X}^{\prime} \boldsymbol{\mu}=\left[\mu_{m} \mu_{S M B} \mu_{H M L}\right]^{\prime} .
$$


This result can also be found by imposing the restriction that $a_{0}$ equals zero in (A.4) and solving for $\mathbf{a}_{1}$. In this case one finds that $\mathbf{a}_{1}$ equals the right hand side in (A.7), as it should. Again a test of the CAPM in a cross-sectional GLS regression without an intercept is a special case, where $\mathbf{W}=\boldsymbol{\Sigma} \mathbf{x}_{m} / \sigma_{m}^{2}=\boldsymbol{\beta}_{m}$ and $A=\mu_{m}$.

These results are quite general. If the cross-sectional regression is run with an intercept, then all included portfolios that have weights which sum to a value other than zero-values that can be normalized to one-will "share" their contribution with the intercept term. In contrast, all portfolios that have zero-weight will have coefficients that are immune to the inclusion of an intercept. As a result, theoretical predictions about coefficient values of zero-weight portfolios will be found to hold in the model with an intercept, while those for unit-weight portfolios will almost certainly not hold exactly and are less likely to hold statistically.

If a GLS regression contains an intercept and factor loadings from zero-weight portfolios only

$$
\mathbf{A}^{\prime}=\left[\begin{array}{lll}
a / c & \mu_{S M B} & \mu_{H M L}
\end{array}\right] .
$$

This follows directly from equation (A.11), recognizing that $\mathbf{I}^{\prime} \mathbf{X} \Sigma^{-1}=\mathbf{0}$. If the GLS regression does not contain an intercept

$$
\mathbf{A}^{\prime}=\left[\begin{array}{ll}
\mu_{S M B} & \mu_{H M L}
\end{array}\right] .
$$

However, the OLS regression results are completely different. For example, consider the case where the CAPM is true and we run an OLS regression with an intercept. With 360 observations the average values of the slope coefficients on the $S M B$ and $H M L$ portfolio are 0.07 and -0.13 , which are close to the factor expected returns of 0.05 and -0.12 . The coefficients are statistically significant from zero $5 \%$ and $8 \%$ of the time in 2,000 simulations. When the regression is run 
without an intercept, the average values of the slope coefficients are 5 to 10 times larger: 0.51 and -0.62 , respectively. Moreover, both are statistically significant 35\% of the time.

\section{A.2 The CAPM and FF three-factor model}

In this section of the appendix we give a more complete discussion of how to reverse engineer the CAPM and FF three-factor pricing equations so that the market portfolio will be either MV-efficient or multifactor-efficient. The single-constraint MV problem with a riskfree asset is

$$
\max \mathrm{L}=t \boldsymbol{\mu}^{\prime} \mathbf{x}+t r x_{r}-1 / 2 \mathbf{x}^{\prime} \boldsymbol{\Sigma} \mathbf{x}+\lambda\left(1-\mathbf{l}^{\prime} \mathbf{x}-x_{r}\right),
$$

where $\boldsymbol{\mu}, \mathbf{x}$ and $\mathbf{~}$ are $n$-vectors containing unity plus expected rates of return, portfolio weights and ones, respectively; $\boldsymbol{\Sigma}$ is an $n \times n$ positive-definite covariance matrix of asset returns; $r$ is unity plus the riskfree rate; $\lambda$ is a Lagrange multiplier associated with the budget constraint $\mathbf{\mathbf { t }} \mathbf{x}+x_{r}=1 ; x_{r}$ is the fraction of wealth either lent or borrowed; and $t$ is a scalar risk tolerance parameter. Please note that we employ the same notation for returns in the text and appendix. But in the appendix $\boldsymbol{\mu}$ and $r$ contain unity plus rates of return. Finally, vectors and matrices are set in bold type, vectors are column vectors, a prime indicates transposition, e.g., $\mathbf{x}^{\prime}$ is the row vector corresponding to the column vector $\mathbf{x}$, and scalars are italicized.

The CAPM holds when the positively weighted market portfolio is the solution to equation (A.1). Although the equilibrating process underlying the CAPM guarantees that the market portfolio will be the efficient tangency portfolio, it takes a little ingenuity to construct examples where this holds. Best and Grauer (1985) show that the "trick" is to work backwards through the efficient set mathematics. Let $\mathbf{x}_{m}$ be an $n$-vector containing the weights in the market portfolio. 
Then, take $\boldsymbol{\Sigma}$ and $\mathbf{x}_{m}$ as given, and construct a set of $\left(\boldsymbol{\Sigma}, \mathbf{x}_{m}\right)$-compatible (or SML) means that makes $\mathbf{x}_{m}$ the optimal solution to equation (A.9). The CAPM means are

$$
\boldsymbol{\mu}_{C A P M}=\theta_{r} \mathbf{\imath}+\theta_{m} \mathbf{\Sigma} \mathbf{x}_{m},
$$

where $\theta_{r}=\lambda\left(t_{m}\right) / t_{m}=r$ and $\theta_{m}=\left(\mu_{m}-r\right) / \sigma_{m}^{2}=1 / t_{m}$ are scalar parameters, $\mu_{m}$ and $\sigma_{m}^{2}$ are the expected return and variance of the market portfolio, $\boldsymbol{\Sigma} \mathbf{x}_{m}$ is an $n$-vector whose $j$ th element, $\operatorname{cov}\left(r_{j}, r_{m}\right)$, is the covariance of the return on security $j$ with the return on the market portfolio, and $t_{m}$ is the risk tolerance parameter of a representative investor who neither borrows nor lends. If we substitute equation (A.10) into equation (A.9) and solve for $t=t_{m}=t_{\tan }=1 /(a-r c)$, then the market portfolio $\mathbf{x}_{m}$ is the tangency portfolio. Alternatively, the SML may be written as

$$
\boldsymbol{\mu}_{C A P M}=r \mathbf{l}+\left(\mu_{m}-r\right) \boldsymbol{\beta}_{m},
$$

where by definition $\boldsymbol{\beta}_{m}=\boldsymbol{\Sigma} \mathbf{x}_{m} / \sigma_{m}^{2}$.

Fama (1996) shows that Merton's (1973) intertemporal capital asset pricing model (ICAPM), like the Sharpe-Lintner CAPM, holds when the market portfolio is the optimal solution to a constrained MV problem. In this case, Fama calls the market multifactor efficient. The FF threefactor model may be viewed as a special case of Merton's model and Fama's (1996) analysis. The FF three-factor model holds when the market portfolio is the optimal solution to

$$
\max L=T \boldsymbol{\mu}^{\prime} \mathbf{x}+t r x_{r}-(1 / 2) \mathbf{x}^{\prime} \boldsymbol{\Sigma} \mathbf{x}+\lambda\left(1-\mathbf{\imath}^{\prime} \mathbf{x}-x_{r}\right)+\lambda_{S M B}\left(\sigma_{m S M B}-\mathbf{x}^{\prime} \Sigma \mathbf{x}_{S M B}\right)+\lambda_{H M L}\left(\sigma_{m H M L}-\mathbf{x}^{\prime} \Sigma \mathbf{x}_{H M L}\right),(\mathrm{A}
$$

where $\mathbf{x}_{S M B}$ and $\mathbf{x}_{H M L}$ are $n$-vectors containing the weights in the $S M B$ and $H M L$ portfolios, the $j$ th elements of $\mathbf{\Sigma} \mathbf{x}_{S M B}$ and $\mathbf{\Sigma} \mathbf{x}_{H M L}$ are $\operatorname{cov}\left(r_{j}, r_{S M B}\right)$ and $\operatorname{cov}\left(r_{j}, r_{H M L}\right)$, $\sigma_{m S M B}=\mathbf{x}_{m}{ }^{\prime} \boldsymbol{\Sigma} \mathbf{x}_{S M B}=\operatorname{cov}\left(r_{m}, r_{S M B}\right), \sigma_{m H M L}=\mathbf{x}_{m}{ }^{\prime} \boldsymbol{\Sigma} \mathbf{x}_{H M L}=\operatorname{cov}\left(r_{m}, r_{H M L}\right)$ and $\lambda, \lambda_{S M B}$ and $\lambda_{H M L}$ are Lagrange multipliers associated with the constraints on the covariances of the returns on the 
optimal portfolio with the returns on the $S M B$ and $H M L$ portfolios, respectively. In order to make the market portfolio multifactor efficient, i.e., to make $\mathbf{x}_{m}$ the optimal solution to equation (A.12), we extend the idea Best and Grauer (1985) used to construct $\left(\boldsymbol{\Sigma}, \mathbf{x}_{m}\right)$-compatible means for the CAPM. Once again we work backwards through the efficient set mathematics. The FF means are

$$
\boldsymbol{\mu}_{F F}=\theta_{r} \mathbf{l}+\theta_{m} \boldsymbol{\Sigma} \mathbf{x}_{m}+\theta_{S M B} \boldsymbol{\Sigma} \mathbf{x}_{S M B}+\theta_{H M L} \boldsymbol{\Sigma} \mathbf{x}_{H M L},
$$

where $\theta_{r}=\lambda\left(t_{m}\right) / t_{m}=r, \theta_{m}=1 / t_{m}, \theta_{S M B}=\lambda_{S M B}\left(t_{m}\right) / t_{m}$ and $\theta_{H M L}=\lambda_{H M L}\left(t_{m}\right) / t_{m}$. If we substitute equation (A.13) into equation (A.12) and solve for $t=t_{m}=t_{\text {tan }}=1 / t(a-r c)$, then the market portfolio $\mathbf{x}_{m}$ is the optimal solution. Thus, the factors are priced, i.e., $\theta_{S M B}$ and $\theta_{H M L}$ are not equal to zero when the constraints on the covariances of the returns on the market portfolio with the returns on the $S M B$ and $H M L$ portfolios are binding. Alternatively, the FF pricing equation may be written as

$$
\boldsymbol{\mu}_{F F}=r \mathbf{\imath}+\left(\mu_{m}-r\right) \mathbf{b}_{m}+\mu_{S M B} \mathbf{b}_{S M B}+\mu_{H M L} \mathbf{b}_{H M L},
$$

where $\mathbf{b}_{m}, \mathbf{b}_{S M B}$ and $\mathbf{b}_{H M L}$ are $n$-vectors containing the factor sensitivities of the securities to the market, $S M B$ and $H M L$ portfolios.

To see the equivalence of the FF pricing equations (A.13) and (A.14), let $\mathbf{X}=\left[\mathbf{x}_{m}, \mathbf{x}_{S M B}, \mathbf{x}_{H M L}\right]$ be an $n \times 3$ matrix containing the market, $S M B$ and $H M L$ portfolios; $\boldsymbol{\Theta}^{\prime}=\left[\theta_{m}, \theta_{S M B}, \theta_{H M L}\right]$ be a vector containing the risk premiums for the market, $S M B$ and $H M L$ portfolios when the FF model is written in covariance form; $\boldsymbol{\Omega}=\mathbf{X}^{\mathbf{\Sigma} \boldsymbol{\Sigma} \mathbf{X}}$ be a $3 \times 3$ matrix containing the covariances between the market, $S M B$ and $H M L$ portfolios; $\mathbf{B}=\boldsymbol{\Sigma} \mathbf{X} \boldsymbol{\Omega}^{-1}=\left[\mathbf{b}_{m}, \mathbf{b}_{S M B}, \mathbf{b}_{H M L}\right]$ be an $n \times 3$ matrix of factor loadings; and 
$\boldsymbol{\mu}_{F a c}^{\prime}=\left[\mu_{m}-r, \mu_{S M B}, \mu_{H M L}\right]$ be a vector containing the risk premiums for the market, $S M B$ and $H M L$ portfolios when the FF model is written in terms of the factor loadings. Then, the FF pricing equations (A.13) and (A.14) may be written more compactly as

$$
\boldsymbol{\mu}_{F F}=r \mathbf{\imath}+\mathbf{\Sigma X \Theta},
$$

and

$$
\boldsymbol{\mu}_{F F}=r \mathbf{\imath}+\mathbf{B} \boldsymbol{\mu}_{F a c}
$$

When we pre-multiply equation (A.7) by $\mathbf{X}^{\prime}$, we see that

$$
\boldsymbol{\mu}_{F a c}=\mathbf{\Omega} \boldsymbol{\Theta} .
$$

It follows from equations (A.2) and (A.5) that the CAPM is a special case of the FF model, where $\theta_{S M B}=\theta_{H M L}=0$. But, perhaps surprisingly, equations (A.8) and (A.9) show that the CAPM is a special case of equation (A.6) when $\mu_{S M B}$ and $\mu_{H M L}$ are not equal to zero, unless the factors are orthogonal to each other. 
Table 1

Population Values of Weights in the Market, Small Minus Big and High Minus Low Portfolios The weights in the market portfolio sum to one and the weights in the small minus big and high minus low portfolios sum to zero.

\begin{tabular}{|c|c|c|c|c|c|}
\hline \multirow[b]{2}{*}{ Size } & \multicolumn{5}{|c|}{ Book-to-Market Equity Quintiles } \\
\hline & Low / Growth & 2 & 3 & 4 & High / Value \\
\hline \multicolumn{6}{|c|}{ Panel A: Market Portfolio Weights (times 100) } \\
\hline Small & 0.8 & 0.5 & 0.5 & 0.5 & 0.7 \\
\hline 2 & 1.1 & 0.8 & 0.8 & 0.7 & 0.6 \\
\hline 3 & 2.0 & 1.4 & 1.4 & 1.2 & 0.9 \\
\hline 4 & 4.0 & 3.0 & 2.8 & 2.5 & 1.6 \\
\hline Big & 29.0 & 15.1 & 12.5 & 10.4 & 5.2 \\
\hline \multicolumn{6}{|c|}{ Panel B: Small Minus Big Portfolio Weights (times 100) } \\
\hline Small & 9.9 & 3.5 & 3.1 & 6.4 & 8.5 \\
\hline 2 & 13.7 & 9.8 & 5.0 & 4.7 & 7.5 \\
\hline 3 & -1.3 & -0.9 & 9.1 & 7.9 & 10.9 \\
\hline 4 & -2.6 & -3.5 & -3.3 & -9.0 & -5.8 \\
\hline Big & -18.7 & -9.8 & -14.5 & -12.0 & -18.5 \\
\hline \multicolumn{6}{|c|}{ Panel C: High Minus Low Portfolio Weights (times 100) } \\
\hline Small & -14.8 & 0.0 & 0.0 & 9.7 & 12.7 \\
\hline 2 & -20.6 & -14.7 & 0.0 & 0.0 & 11.3 \\
\hline 3 & -1.9 & -1.4 & 0.0 & 0.0 & 16.3 \\
\hline 4 & -3.9 & 0.0 & 0.0 & 13.5 & 8.8 \\
\hline Big & -28.1 & -14.7 & 0.0 & 0.0 & 27.7 \\
\hline
\end{tabular}


Table 2

Population Values of Market Portfolio Betas, Equal-Weighted Portfolio Betas, and Fama-French Loadings on the Market, Small Minus Big, and High Minus Low Factors

\begin{tabular}{|c|c|c|c|c|c|}
\hline \multirow[b]{2}{*}{ Size } & \multicolumn{5}{|c|}{ Book-to-Market Equity Quintiles } \\
\hline & Low / Growth & 2 & 3 & 4 & High / Value \\
\hline \multicolumn{6}{|c|}{ Panel A: Market Portfolio Betas } \\
\hline Small & 1.26 & 1.11 & 1.02 & 0.95 & 0.98 \\
\hline 2 & 1.28 & 1.09 & 0.99 & 0.92 & 1.00 \\
\hline 3 & 1.22 & 1.03 & 0.93 & 0.87 & 0.95 \\
\hline 4 & 1.13 & 1.02 & 0.93 & 0.87 & 0.98 \\
\hline Big & 1.15 & 0.99 & 0.85 & 0.81 & 0.81 \\
\hline \multicolumn{6}{|c|}{ Panel B: Equal-Weighted Portfolio Betas } \\
\hline Small & 1.39 & 1.24 & 1.14 & 1.07 & 1.12 \\
\hline 2 & 1.32 & 1.16 & 1.05 & 0.98 & 1.09 \\
\hline 3 & 1.20 & 1.04 & 0.95 & 0.88 & 1.01 \\
\hline 4 & 1.03 & 0.97 & 0.89 & 0.84 & 0.99 \\
\hline Big & 0.77 & 0.77 & 0.68 & 0.68 & 0.74 \\
\hline \multicolumn{6}{|c|}{ Panel C: Fama-French Loadings on the Market Factor } \\
\hline Small & 1.02 & 1.06 & 0.99 & 0.98 & 1.04 \\
\hline 2 & 0.99 & 0.95 & 0.97 & 0.93 & 1.07 \\
\hline 3 & 1.15 & 1.01 & 0.92 & 0.88 & 1.05 \\
\hline 4 & 1.07 & 1.03 & 0.96 & 0.97 & 1.08 \\
\hline Big & 1.08 & 0.98 & 0.91 & 0.88 & 0.99 \\
\hline \multicolumn{6}{|c|}{ Panel D: Fama-French Loadings on the Small Minus Big Factor } \\
\hline Small & 1.35 & 1.02 & 0.91 & 0.98 & 1.13 \\
\hline 2 & 1.22 & 0.95 & 0.76 & 0.68 & 0.90 \\
\hline 3 & 0.54 & 0.50 & 0.66 & 0.56 & 0.82 \\
\hline 4 & 0.28 & 0.27 & 0.26 & 0.17 & 0.31 \\
\hline Big & -0.33 & -0.12 & -0.17 & -0.09 & -0.07 \\
\hline \multicolumn{6}{|c|}{ Panel E: Fama-French Loadings on the High Minus Low Factor } \\
\hline Small & -0.39 & 0.24 & 0.28 & 0.54 & 0.76 \\
\hline 2 & -0.62 & -0.16 & 0.26 & 0.33 & 0.68 \\
\hline 3 & -0.04 & 0.13 & 0.26 & 0.31 & 0.74 \\
\hline 4 & -0.11 & 0.14 & 0.23 & 0.48 & 0.55 \\
\hline Big & -0.42 & -0.08 & 0.15 & 0.28 & 0.71 \\
\hline
\end{tabular}




\section{Table 3}

Population Values of Fama-French Means, CAPM Means, and Alphas

The Fama-French means with the parameters set to historical values are generated from

$$
\mu_{F F}=0.5 \mathfrak{\imath}+0.5 \mathbf{b}_{m}+0.417 \mathbf{b}_{S M B}+0.533 \mathbf{b}_{H M L} .
$$

The CAPM means may be generated in one of two equivalent ways

$$
\begin{gathered}
\mu_{C A P M}=0.5 \mathfrak{\imath}+0.5 \beta_{m} \\
\mu_{C A P M}=\mu_{F F}=0.5 \mathfrak{\imath}+0.5 \mathbf{b}_{m}+0.054 \mathbf{b}_{S M B}-0.124 \mathbf{b}_{H M L} .
\end{gathered}
$$

\begin{tabular}{|c|c|c|c|c|c|}
\hline \multirow[b]{2}{*}{ Size } & \multicolumn{5}{|c|}{ Book-to-Market Equity Quintiles } \\
\hline & Low / Growth & 2 & 3 & 4 & High / Value \\
\hline \multicolumn{6}{|c|}{ Panel A: Fama-French Means } \\
\hline Small & 1.36 & 1.58 & 1.52 & 1.69 & 1.90 \\
\hline 2 & 1.17 & 1.29 & 1.44 & 1.42 & 1.78 \\
\hline 3 & 1.28 & 1.28 & 1.38 & 1.34 & 1.76 \\
\hline 4 & 1.09 & 1.20 & 1.21 & 1.31 & 1.46 \\
\hline Big & 0.67 & 0.90 & 0.97 & 1.05 & 1.35 \\
\hline \multicolumn{6}{|c|}{ Panel B: CAPM Means } \\
\hline Small & 1.13 & 1.06 & 1.01 & 0.98 & 0.99 \\
\hline 2 & 1.14 & 1.05 & 0.99 & 0.96 & 1.00 \\
\hline 3 & 1.11 & 1.02 & 0.96 & 0.93 & 0.98 \\
\hline 4 & 1.06 & 1.01 & 0.97 & 0.93 & 0.99 \\
\hline Big & 1.07 & 0.99 & 0.93 & 0.90 & 0.90 \\
\hline \multicolumn{6}{|c|}{ Panel C: Alphas (Fama-French Means - CAPM Means) } \\
\hline Small & 0.23 & 0.52 & 0.51 & 0.71 & 0.91 \\
\hline 2 & 0.03 & 0.24 & 0.45 & 0.46 & 0.78 \\
\hline 3 & 0.17 & 0.26 & 0.42 & 0.41 & 0.78 \\
\hline 4 & 0.03 & 0.19 & 0.24 & 0.38 & 0.47 \\
\hline Big & -0.40 & -0.09 & 0.04 & 0.15 & 0.45 \\
\hline
\end{tabular}


Table 4

Univariate cross-sectional tests of the CAPM

The tests are based on the cross-sectional regressions $\bar{r}_{j}-\bar{r}=\gamma_{0}+\gamma_{1} \hat{\beta}_{j}+e_{j}$ where the betas are estimated from the time-series regression $r_{j t}-r_{t}=\alpha_{j}+\left(r_{m t}-r_{t}\right) \beta_{j}+e_{j t}$. In each of 2000 replications, the size of the test is $5 \%$ when sample sizes of $120,360,600,1,200,3,600$ or 6,000 are examined. The null hypothesis is that the intercept (slope) is equal to zero. The alternative is that the intercept (slope) is not equal to zero.

\begin{tabular}{|c|c|c|c|c|c|c|c|}
\hline \multicolumn{8}{|c|}{ Panel A: The CAPM is true } \\
\hline & & \multicolumn{3}{|c|}{ Market portfolio betas } & \multicolumn{3}{|c|}{ Equal-weighted portfolio betas } \\
\hline & & intercept & $\beta_{\mathrm{m}}$ & $\mathbf{R}^{2}$ & intercept & $\beta_{\mathrm{e}}$ & $\mathbf{R}^{2}$ \\
\hline & Population Coefficient & 0.00 & 0.50 & 1.00 & 0.24 & 0.26 & 0.59 \\
\hline \multirow[t]{2}{*}{$\mathrm{T}=120$} & Average Coefficient & 0.21 & 0.28 & 0.07 & 0.28 & 0.21 & 0.09 \\
\hline & Percent Rejected & 8 & 4 & & 8 & 4 & \\
\hline \multirow[t]{2}{*}{$\mathrm{T}=360$} & Average Coefficient & 0.09 & 0.41 & 0.10 & 0.26 & 0.23 & 0.10 \\
\hline & Percent Rejected & 6 & 9 & & 10 & 7 & \\
\hline \multirow[t]{2}{*}{$\mathrm{T}=600$} & Average Coefficient & 0.05 & 0.44 & 0.12 & 0.26 & 0.24 & 0.11 \\
\hline & Percent Rejected & 5 & 14 & & 12 & 9 & \\
\hline \multirow[t]{2}{*}{$T=1,200$} & Average Coefficient & 0.03 & 0.47 & 0.17 & 0.25 & 0.25 & 0.14 \\
\hline & Percent Rejected & 5 & 24 & & 18 & 13 & \\
\hline \multirow[t]{2}{*}{$\mathrm{T}=3,600$} & Average Coefficient & 0.01 & 0.49 & 0.32 & 0.24 & 0.26 & 0.22 \\
\hline & Percent Rejected & 4 & 61 & & 43 & 36 & \\
\hline \multirow[t]{2}{*}{$\mathrm{T}=6,000$} & Average Coefficient & 0.01 & 0.49 & 0.44 & 0.24 & 0.26 & 0.28 \\
\hline & Percent Rejected & 5 & 83 & & 61 & 53 & \\
\hline
\end{tabular}

Panel B: The FF three-factor model is true with parameters set to historic values

\begin{tabular}{|c|c|c|c|c|c|c|c|}
\hline & & \multicolumn{3}{|c|}{ Market portfolio betas } & \multicolumn{3}{|c|}{ Equal-weighted portfolio betas } \\
\hline & & intercept & $\beta_{m}$ & $\mathbf{R}^{2}$ & intercept & $\beta_{\mathrm{e}}$ & $\mathbf{R}^{2}$ \\
\hline & Population Coefficient & 1.08 & -0.24 & 0.01 & 0.11 & 0.73 & 0.24 \\
\hline \multirow[t]{2}{*}{$\mathrm{T}=120$} & Average Coefficient & 0.98 & -0.16 & 0.06 & 0.23 & 0.59 & 0.11 \\
\hline & Percent Rejected & 28 & 5 & & 9 & 10 & \\
\hline \multirow[t]{2}{*}{$\mathrm{T}=360$} & Average Coefficient & 1.04 & -0.22 & 0.06 & 0.16 & 0.66 & 0.14 \\
\hline & Percent Rejected & 49 & 8 & & 8 & 26 & \\
\hline \multirow[t]{2}{*}{$\mathrm{T}=600$} & Average Coefficient & 1.05 & -0.23 & 0.05 & 0.15 & 0.69 & 0.16 \\
\hline & Percent Rejected & 63 & 9 & & 8 & 41 & \\
\hline \multirow[t]{2}{*}{$T=1200$} & Average Coefficient & 1.07 & -0.23 & 0.04 & 0.13 & 0.71 & 0.19 \\
\hline & Percent Rejected & 88 & 11 & & 9 & 71 & \\
\hline \multirow[t]{2}{*}{$\mathrm{T}=3600$} & Average Coefficient & 1.08 & -0.24 & 0.22 & 0.11 & 0.72 & 0.22 \\
\hline & Percent Rejected & 100 & 22 & & 13 & 99 & \\
\hline \multirow[t]{2}{*}{$\mathrm{T}=6000$} & Average Coefficient & 1.08 & -0.24 & 0.02 & 0.11 & 0.72 & 0.23 \\
\hline & Percent Rejected & 100 & 30 & & 19 & 100 & \\
\hline
\end{tabular}


Table 5

Tests of whether beta alone explains the cross-section of expected returns

The tests are based on the cross-sectional regressions $\bar{r}_{j}-\bar{r}=\gamma_{0}+\gamma_{1} \hat{\beta}_{j}+\gamma_{2} \hat{b}_{S M B j}+\gamma_{3} \hat{b}_{H M L j}+e_{j}$ and $\bar{r}_{j}-\bar{r}=\gamma_{0}+\gamma_{1} \hat{b}_{m j}+\gamma_{2} \hat{b}_{S M B j}+\gamma_{3} \hat{b}_{H M L j}+e_{j}$ where the factor loadings are estimated from the time-series regressions $r_{j t}-r_{t}=\alpha_{j}+\left(r_{m t}-r_{t}\right) \beta_{j}+e_{j t}$ and $r_{j t}-r_{t}=\alpha_{j}+\left(r_{m t}-r_{t}\right) b_{j m}+r_{S M B t} b_{j S M B}+r_{H M L t} b_{j H M L}+e_{j t}$. In each of 2000 replications, the size of the test is $5 \%$ when sample sizes of 360 or 3,600 are examined. The null hypothesis is that the intercept (slope) is equal to zero. The alternative is that the intercept (slope) is not equal to zero.

\begin{tabular}{|c|c|c|c|c|c|c|}
\hline \multicolumn{7}{|c|}{ Panel A: CAPM is true, GLS regression with Shanken correction } \\
\hline & & intercept & $\mathbf{b}_{m}$ & $\mathbf{b}_{S M B}$ & $\mathbf{b}_{H M L}$ & $\mathbf{R}^{2}$ \\
\hline \multirow[t]{2}{*}{$\mathrm{T}=360$} & Average Coefficient & 0.10 & 0.39 & 0.05 & -0.12 & 0.54 \\
\hline & Percent Rejected & 5 & 8 & 7 & 11 & \\
\hline \multirow[t]{2}{*}{$\mathrm{T}=3,600$} & Average Coefficient & 0.03 & 0.46 & 0.05 & -0.12 & 0.68 \\
\hline & Percent Rejected & 5 & 36 & 14 & 39 & \\
\hline \multicolumn{7}{|c|}{ Panel B: CAPM is true, equal-weighted portfolio betas, GLS regression with Shanken correction } \\
\hline & & intercept & $\beta_{\mathrm{e}}$ & $\mathbf{b}_{S M B}$ & $\mathbf{b}_{H M L}$ & $\mathbf{R}^{2}$ \\
\hline \multirow[t]{2}{*}{$\mathrm{T}=360$} & Average Coefficient & 0.22 & 0.30 & -0.05 & -0.08 & 0.52 \\
\hline & Percent Rejected & 7 & 5 & 6 & 6 & \\
\hline \multirow[t]{2}{*}{$\mathrm{T}=3,600$} & Average Coefficient & 0.14 & 0.40 & -0.08 & -0.07 & 0.67 \\
\hline & Percent Rejected & 10 & 23 & 10 & 16 & \\
\hline \multicolumn{7}{|c|}{ Panel C: CAPM is true, market portfolio betas, GLS regression } \\
\hline & & intercept & $\beta_{\mathrm{m}}$ & $\mathbf{b}_{S M B}$ & $\mathbf{b}_{H M L}$ & $\mathbf{R}^{2}$ \\
\hline \multirow[t]{2}{*}{$\mathrm{T}=360$} & Average Coefficient & 0.17 & 0.31 & 0.02 & -0.04 & 0.52 \\
\hline & Percent Rejected & 9 & 10 & 38 & 21 & \\
\hline \multirow[t]{2}{*}{$\mathrm{T}=3,600$} & Average Coefficient & 0.03 & 0.46 & 0.00 & -0.01 & 0.68 \\
\hline & Percent Rejected & 7 & 34 & 31 & 17 & \\
\hline \multicolumn{7}{|c|}{ Panel D: CAPM is true, market portfolio betas, GLS regression with Shanken correction } \\
\hline & & intercept & $\beta_{\mathrm{m}}$ & $\mathbf{b}_{S M B}$ & $\mathbf{b}_{H M L}$ & $\mathbf{R}^{2}$ \\
\hline \multirow[t]{2}{*}{$\mathrm{T}=360$} & Average Coefficient & 0.17 & 0.31 & 0.02 & -0.04 & 0.52 \\
\hline & Percent Rejected & 6 & 5 & 6 & 6 & \\
\hline \multirow[t]{2}{*}{$\mathrm{T}=3,600$} & Average Coefficient & 0.03 & 0.46 & 0.00 & -0.01 & 0.68 \\
\hline & Percent Rejected & 5 & 31 & 5 & 6 & \\
\hline \multicolumn{7}{|c|}{ Panel E: FF is true, parameters set to historic values, market portfolio betas, OLS Fama-MacBeth regression } \\
\hline & & intercept & $\mathbf{b}_{m}$ & $\mathbf{b}_{S M B}$ & $\mathbf{b}_{H M L}$ & $\mathbf{R}^{2}$ \\
\hline \multirow[t]{2}{*}{$T=360$} & Average Coefficient & 0.27 & 0.24 & 0.40 & 0.51 & 0.53 \\
\hline & Percent Rejected & 9 & 7 & 51 & 60 & \\
\hline \multirow[t]{3}{*}{$\mathrm{T}=3,600$} & Average Coefficient & 0.05 & 0.45 & 0.42 & 0.53 & 0.91 \\
\hline & Percent Rejected & 6 & 33 & 100 & 100 & \\
\hline & & intercept & $\beta_{m}$ & $\mathbf{b}_{S M B}$ & $\mathbf{b}_{H M L}$ & $\mathbf{R}^{2}$ \\
\hline \multirow[t]{2}{*}{$\mathrm{T}=360$} & Average Coefficient & 0.27 & 0.39 & 0.36 & 0.61 & 0.53 \\
\hline & Percent Rejected & 9 & 8 & 36 & 51 & \\
\hline \multirow[t]{2}{*}{$\mathrm{T}=3,600$} & Average Coefficient & 0.05 & 0.62 & 0.35 & 0.69 & 0.91 \\
\hline & Percent Rejected & 6 & 48 & 100 & 100 & \\
\hline
\end{tabular}



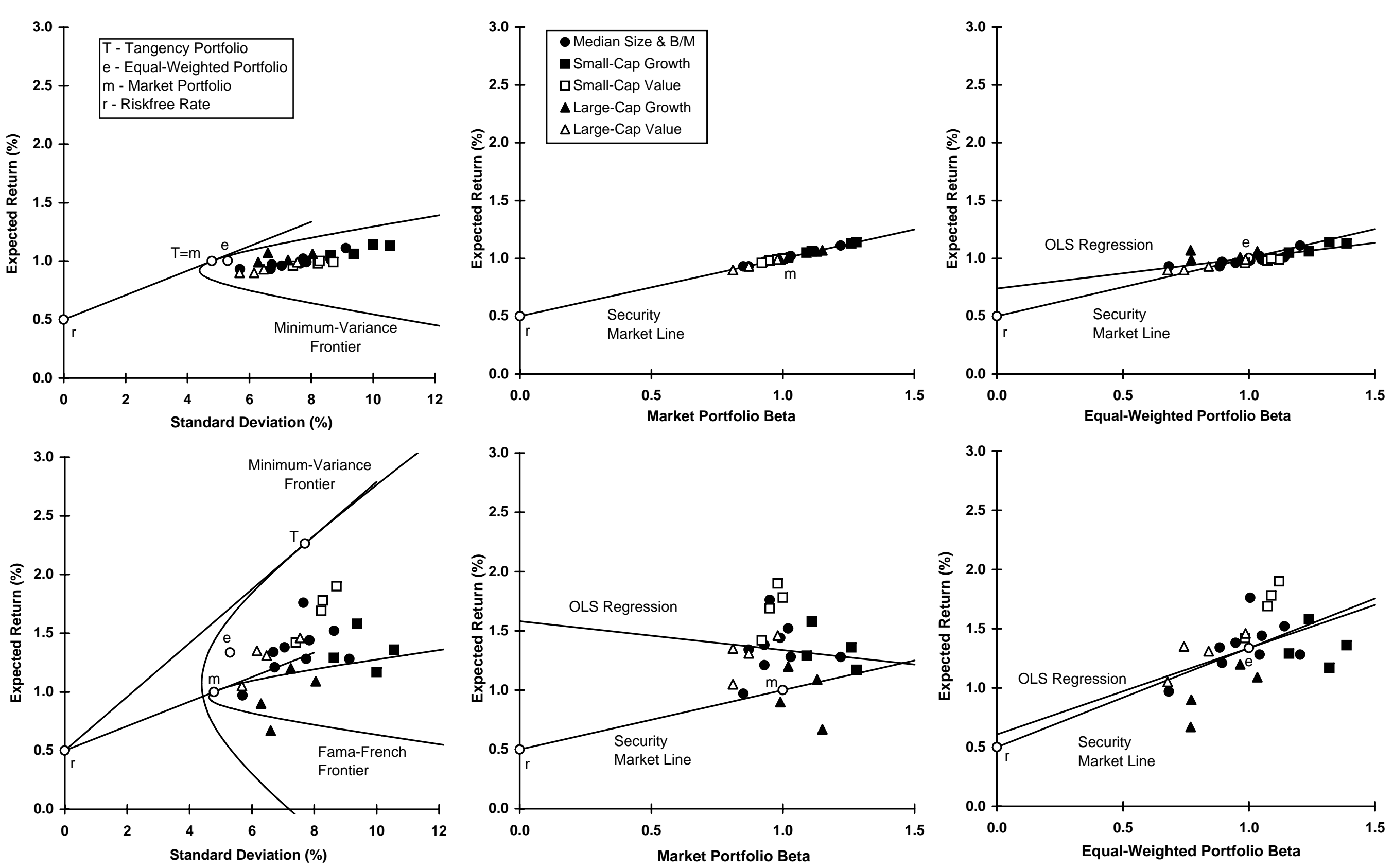

Figure 1. The CAPM is true in the upper figures. OLS and GLS regressions of population expected returns on market portfolio betas yield an intercept of 0.5 and a slope of 0.5 , which are identical to the intercept and slope of the Security Market Line. An OLS (GLS) regression of population expected returns on equal-weighted betas yields an intercept of $0.74(0.74)$ and a slope of $0.26(0.26)$. The Fama-French model is true, with the parameter values set to their historic values, in the lower figures. An OLS (GLS) regression of population expected returns on market portfolio betas yields an intercept of 1.58 (1.46) and a slope of -0.24 (-0.46). An OLS (GLS) regression of the population expected returns on equal-weighted betas yields an intercept of $0.61(0.50)$ and a slope of 0.73 (0.84). 

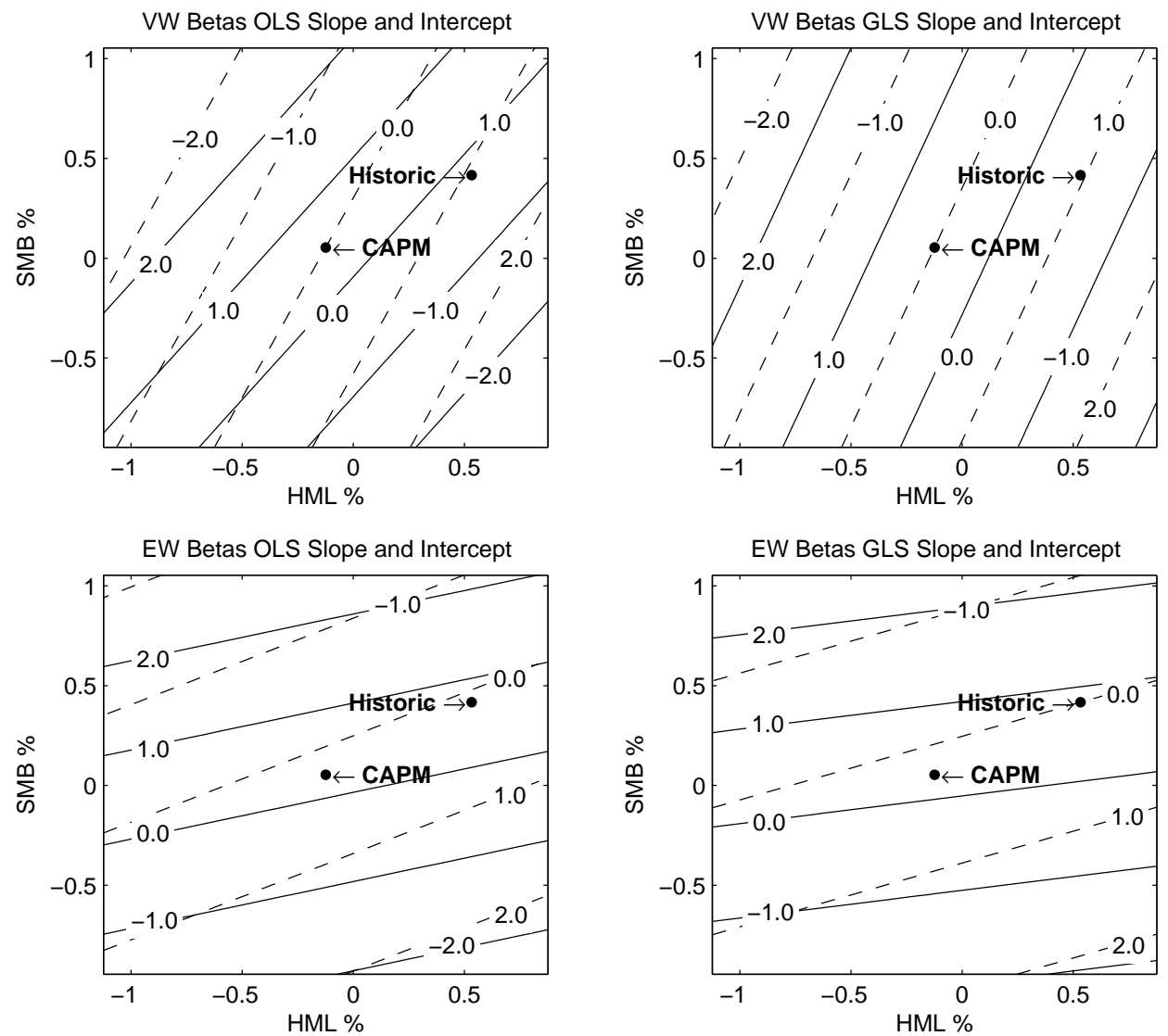

Figure 2: Contours for population intercepts and slopes of OLS and GLS regressions of expected excess returns on market (VW) portfolio betas and equal-weighted (EW) portfolio betas. Contours for population intercepts are dashed lines and slopes are solid lines. In Figures 2-6, CAPM indicates the point where the CAPM is true and Historic indicates the point where the Fama-French pricing equation parameters are consistent with the values estimated by Fama and French (1996). In each figure, the plots are based on the Fama-French pricing equation with the riskfree rate and expected excess return on the market set equal to 0.5 percent per month while the expected returns on the $H M L$ and $S M B$ portfolios vary from -1 to +1 percent per month. The tests employ OLS regressions unless noted otherwise. Where OLS is used the standard errors of the estimates are corrected using the Fama-MacBeth procedure. 
VW Betas, Intercept $=0$

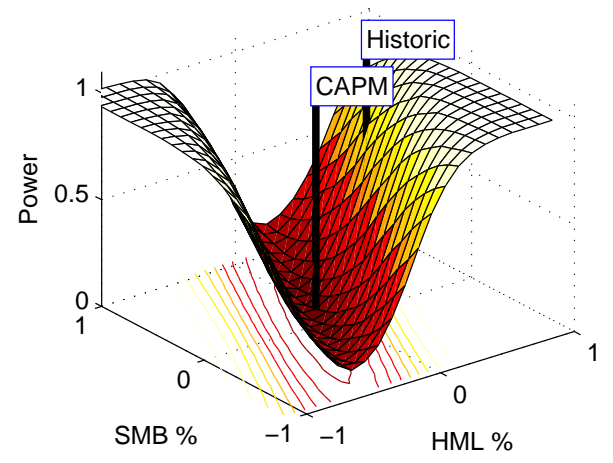

EW Betas, Intercept $=0$

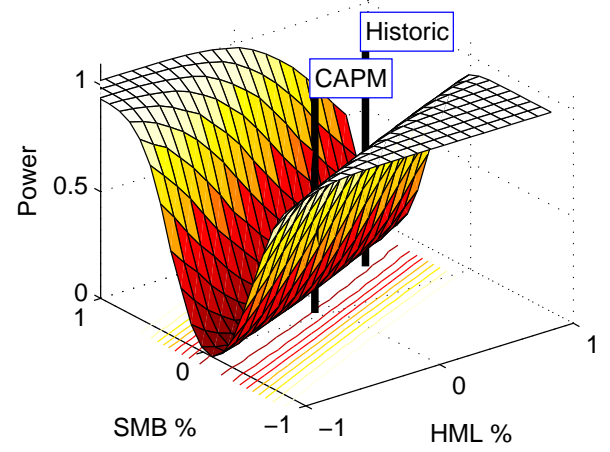

VW Betas, Slope $=0$

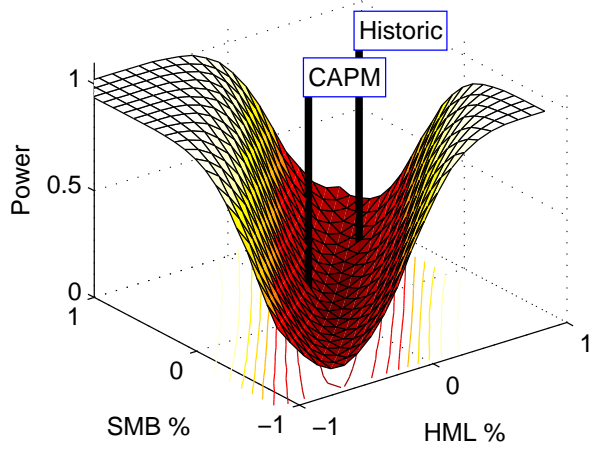

EW Betas, Slope $=0$

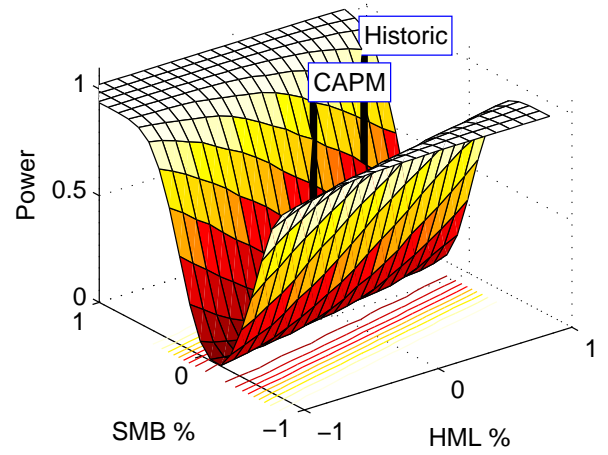

Figure 3: The power of a test of the hypothesis that the intercept (or slope) of an OLS regression of expected excess returns on market (VW) portfolio betas or equalweighted (EW) portfolio betas is equal to zero. All power and R-square surfaces are based on 2000 replications of a test with a size of $5 \%$ and 600 observation unless noted otherwise. 

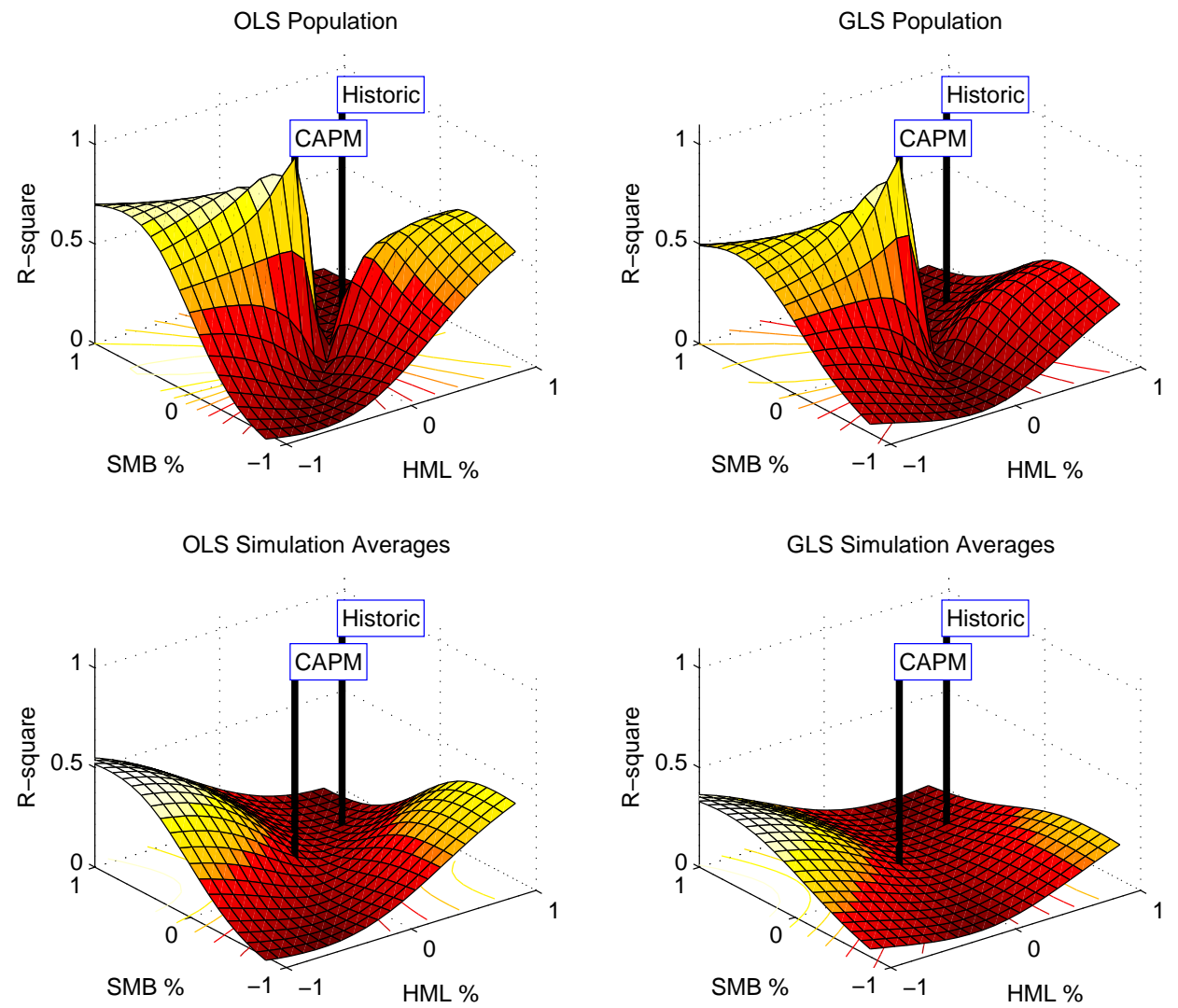

Figure 4: Population R-squares and the average values of R-squares for OLS and GLS regressions of expected excess returns on market portfolio betas. 
GRS, T=120

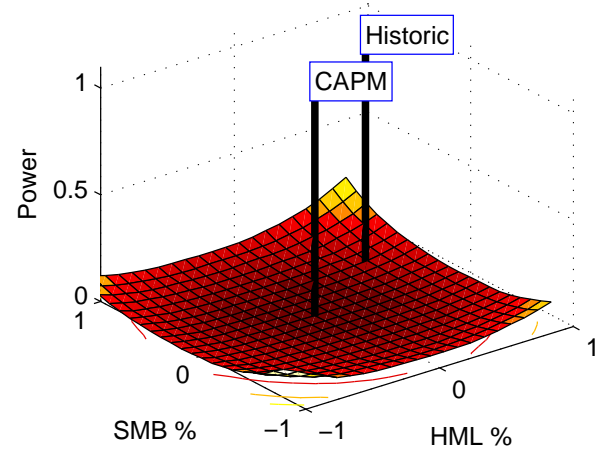

GRS, T $=360$

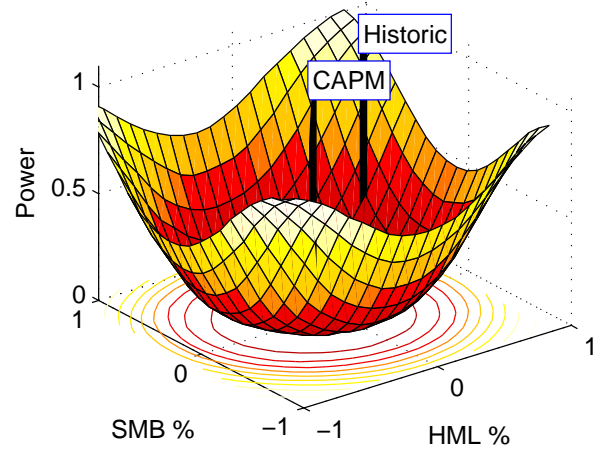

GRS, $T=600$

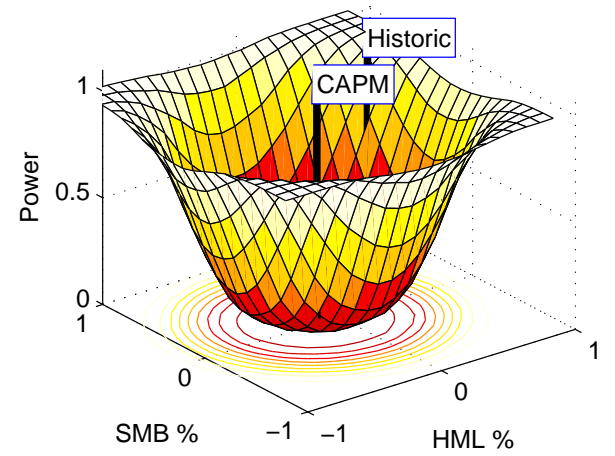

Shanken, $\mathrm{T}=120$

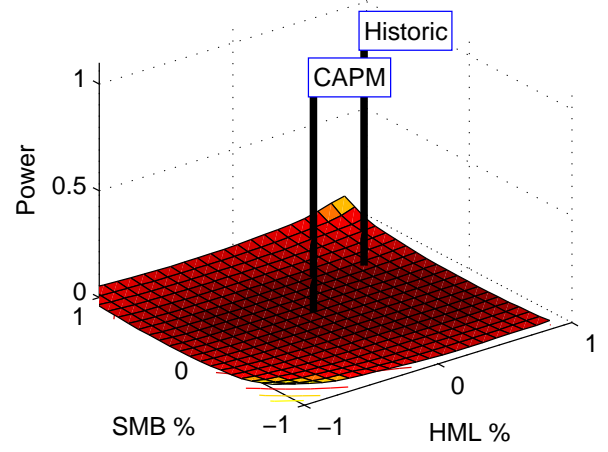

Shanken, $\mathrm{T}=360$

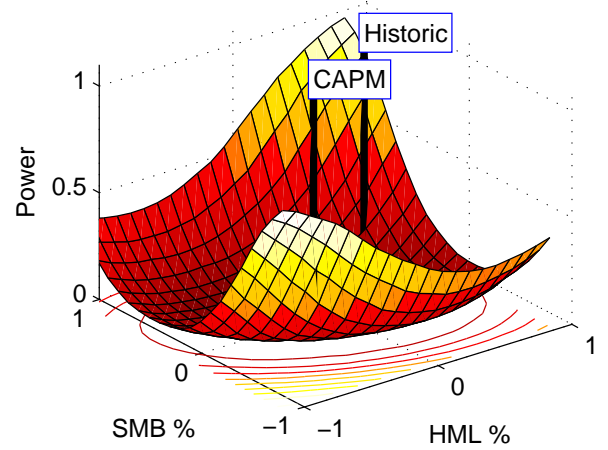

Shanken, $\mathrm{T}=600$

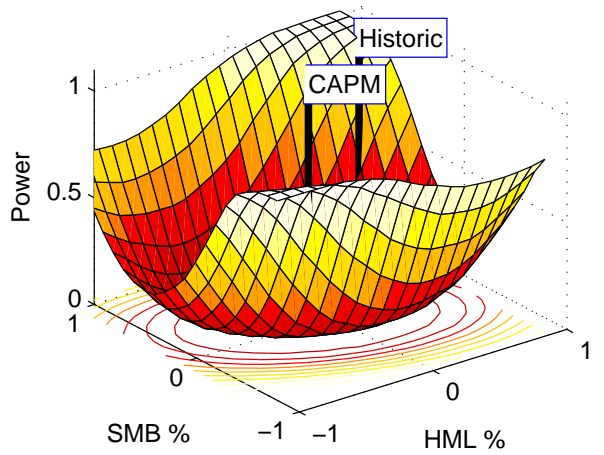

Figure 5: The power of Gibbons, Ross and Shanken's (GRS) multivariate test of the efficiency of the market portfolio and Shanken's multivariate cross-sectional test. The power is based on 2000 replications of a test with a size of $5 \%$ and either $\mathrm{T}=$ 120,360 or 600 observations. 

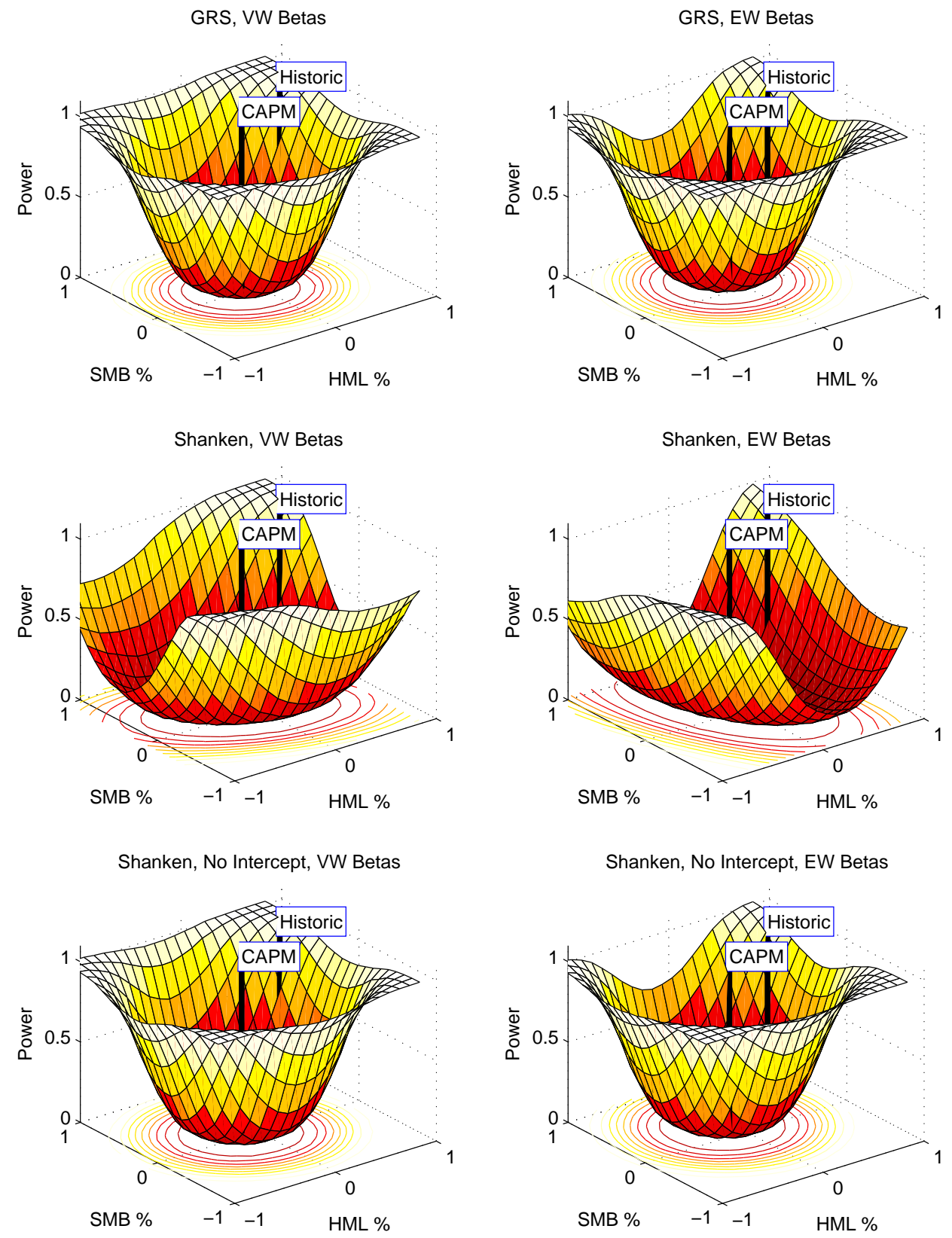

Figure 6: The power of Gibbons, Ross and Shanken's multivariate test, Shanken's multivariate test and Shanken's multivariate test (based on a GLS regression without an intercept) of the efficiency of the market portfolio or the equal-weighted portfolio. 